Universidade de Brasília - UnB

Faculdade de Ciências da Saúde

Programa de Pós-graduação em Ciências da Saúde - PPGCS

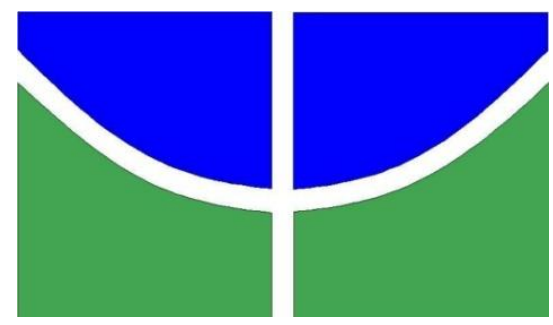

\title{
Pesquisa de Mutações no Gene DVL1 em Pacientes com a Forma Autossômica Dominante da Síndrome de Robinow
}

Pedro Guilherme Alves Rodrigues

\author{
Dissertação apresentada ao Programa de \\ Pós-graduação em Ciências da Saúde da \\ Universidade de Brasília como requisito \\ Parcial para obtenção do título de \\ Mestre em Ciências da Saúde.
}

Orientadora: Dra. Juliana Forte Mazzeu de Araújo 
PEDRO GUILHERME ALVES RODRIGUES

Título:

\section{Pesquisa de Mutações no Gene DVL1 em Pacientes com a Forma Autossômica Dominante da Síndrome de Robinow}

Comissão Examinadora:

Prof. Dra Juliana Forte Mazzeu de Araújo

Faculdade de Medicina-UnB

Prof. Drª Maria de Nazaré Klautau Guimarães

Instituto de Biologia - UnB

Drª Mara Santos Cordoba

Hospital Universitário - UnB

Prof. Dr ${ }^{\text {a }}$ Silviene Fabiana de Oliveira

Instituto de Biologia - UnB

(Suplente) 


\section{AGRADECIMENTOS}

Agradeço imensamente a Deus por estar sempre em meu caminho, desde o início ao fim deste projeto, e sempre colocando pessoas magníficas em minha vida. Pelo conhecimento absorvido e transmitido nessa oportunidade de estar no meio da pesquisa cientifica.

A minha grandiosa mãe Maria Aparecida da Conceição Rodrigues por ser meu porto seguro, onde o amor, carisma e atenção foram primordiais desde o início da minha vida acadêmica. Ao meu pai Vamilson Alves Rodrigues com todo seu conhecimento e exemplo de vitória, sempre apoiando e me instigando a olhar sempre mais a frente, sem vocês essa trajetória não seria a mesma, meus amores paternos.

A minha querida e excelente mulher Alana de Sá Farias, por estar ao meu lado em todos os momentos, se tornando fonte de incentivo, amor, carinho e força em momentos que jamais havia passado. Obrigado e desejo que Deus compense toda a paciência que teve comigo no desenvolver desse trabalho. Ao meu pequeno e lindo filho Bernardo Farias Alves Rodrigues, por me contagiar com o sorriso mais lindo, pelas vezes que me deixou ler artigos enquanto brincava no parquinho de areia, e por me fazer pensar em realizações futuras.

Meu irmão Gustavo Willian Alves Rodrigues por me ajudar com a tradução de artigos em inglês, pela sua atenção em deixar suas atividades em segundo plano para me auxiliar.

A minha admirável e atenciosa orientadora $\operatorname{Dr}^{a}$ Juliana Forte Mazzeu de Araújo, por me acolher desde o estágio na graduação, sempre muito dedicada e uma profissional inigualável, conduziu o desenvolvimento desse trabalho com muita sabedoria, em meio à troca de temas, me confiou um assunto que trabalha a anos, onde pude me aprofundar e tirar dúvidas com a certeza que estava amparado a crescer intelectualmente ao lado de uma Doutora e professora como ela, sonho em alcançar ao menos a metade de sua trajetória.

A todo pessoal do laboratório de Genética da Faculdade de Medicina, que pude acompanhar em um pouco mais de 4 anos de UnB, a ilustríssima e querida Prof $^{-a}$ Dr $^{\mathrm{a}}$ Iris Ferrari, por me presentear com as melhores manhãs, seja nos ensinando ou compartilhando as alegrias da vida, a todas as Doutoras Medicas do 
Ambulatório do Hospital Universitário, aos técnicos Aluísio e Nilza, ao Prof. Luiz Simeoni e a sua irmã Cristina, a Prof. João Estevam, a Drª Pollyanna e a estagiaria Amanda, por partilhar os momentos descontraídos na hora do almoço. A mestra Ariadne, e mestranda Bárbara pelas conversas e discussões dos projetos.

Ao Programa de Pós Graduação em Ciências da Saúde da Faculdade de Ciências da Saúde da Universidade de Brasília por todo suporte acadêmico e administrativo. Incentivo financeiro da CAPES pelo fornecimento da bolsa de aluno mestrando do programa. 


\section{Lista de Abreviaturas}

DNA - Ácido desoxirribonucleico

PCR - Reação em cadeia da Polimerase

RNA - Ácido ribonucleico

DNTPs - Desoxirribonucleotídeos

DSH - Dishevelled

DVL1 - Dishevelled segment polarity protein

ROR2 - Receptor tyrosine kinase-like orphan receptor 2

SR - Síndrome de Robinow

DRS - Síndrome de Robinow autossômica Dominante

SRR - Síndrome de Robinow autossômica Recessiva

WNT5A - Wingless-type MMTV integration site family, member 5A

SSCP - Polimorfismo conformacional de fita simples

CAM - 1- Canal -associated neurons abnormal migration

PCP - Polaridade celular planar

LRP6 - Receptor de lipoproteína 6

PTK7 - Proteína Tyr quinase 7

RYK - Receptor de quinase Tyr

COVESDEM - Costovertebral segmentation defects with mesomelia

MLPA - Multiplex Ligation- dependent Probe Amplification

Fzd - Frizzled

FZD5 (frizzled-5)

TCF - (fator de célula T) 
LEF - (fator potenciador linfóide de ligação)

GSK-3 - glicogênio sintase quinase 3

CK1 - caseína-quinase 1 


\section{Resumo}

A Síndrome de Robinow se caracteriza por dismorfias faciais associadas a encurtamento mesomélico de membros e genitália hipoplásica. Defeitos de segmentação costovertebral que incluem fusões de costelas também podem ser observados e permitem distinguir os pacientes com a forma autossômica recessiva da síndrome daqueles com a forma autossômica dominante. A forma autossômica recessiva é causada por mutações no gene ROR2. Já foram descritos três genes causativos para a forma autossômica dominante da síndrome: WNT5A, DVL1 e $D V L 3$, apesar de muitos pacientes não apresentarem mutações nesses genes. As frequências de mutação em cada um dos genes bem como possíveis correlações genótipo/fenótipo ainda não foram estabelecidas. O objetivo desse trabalho foi identificar novas mutações no gene DVL1 em pacientes com a Síndrome de Robinow autossômica dominante. Foram selecionados onze pacientes originários dos Estados Unidos, Argentina e Inglaterra com características clínicas da forma autossômica dominante da síndrome. O sequenciamento foi realizado a partir de amostras de sangue por sequenciamento Sanger. Identificamos quatro pacientes com mutações em $D V L 1$, sendo três não descritas na literatura e uma ainda não confirmada pela clonagem dos fragmentos de PCR. Comparamos a frequência dos sinais clínicos no grupo de pacientes estudados com aquelas descritas por Mazzeu e cols. (2007) e com as frequências apenas no grupo com mutação em DVL1. As frequências foram semelhantes para a maioria dos sinais clínicos com exceção do hipertelorismo com frequência de 100\%, a língua bífida presente em 7 dos 11 pacientes, hipoplasia do terço médio da face que teve uma frequência de $100 \%$ e anteriormente era de $80 \%$, e a hiperplasia gengival que teve uma frequência de $90 \%$ enquanto que a frequência descrita anteriormente era de $35 \%$. Assim, a descrição clínica detalhada de pacientes com diagnóstico confirmado molecularmente contribui para a definição das frequências dos principais sinais clínicos da forma autossômica dominante da síndrome. No grupo com mutação em DVL1 todos apresentam macrocefalia e nenhum dos pacientes apresenta baixa estatura como já sugerido por White e cols., 2015. O conjunto de novas mutações detectadas no trabalho colabora para um melhor entendimento da etiologia da síndrome e para a caracterização clinica das diferentes formas da síndrome de Robinow. 


\section{Abstract}

Robinow syndrome is characterized by facial dysmophisms associated to mesomelic limb shortening and hypoplastic genitalia. Costovertebral segmentation defects including rib fusions may be present and allow the distinction of the recessive and dominant forms of the syndrome. Autosomal recessive form is caused by mutations in ROR2 gene. Three causative genes have been described for the autosomal dominant form of the syndrome: WNT5A, DVL1, DVL3, although several patients do not present mutations in any of these genes. The frequencies of mutations in each of these genes as well as possible genotype/phenotype correlation have not been stablished. The aim of this study was to identify new mutations in DVL1 gene in patients with autosomal dominant Robinow syndrome. We have included eleven patients from the United States, Argentina and England with clinical signs of the dominant form of the syndrome. Sanger sequencing was performed from blood samples. We identified four patients with mutations in DVL1, three novel and one not yet confirmed by cloning of the PCR fragments. We compared the frequencies of clinical signs of the patients here described and the frequencies previously described by Mazzeu e cols., (2007) and the frequencies only in the group with DVL1 mutations. The frequencies were similar for most clinical signs except for hypertelorism with a $100 \%$ frequency, bifid tongue in $7 / 11$ patients, midface hypoplasia with a $100 \%$ frequency in our group and $80 \%$ in the literature, and gingival hyperplasia with a $90 \%$ frequency in our group and $35 \%$ in the literature. Therefore, a detailed clinical description of patients with a molecularly confirmed diagnosis contributes to a better definition of the frequencies of the main clinical signs of the autosomal dominant form of the syndrome. In the group with mutation in DVL1 all of them have macrocephaly and none of the patients have short stature as previously suggested by White \& cols., 2015. The group of novel mutations detected in our work collaborates to a better understanding of the etiology of the syndrome and the clinical characterization of the different forms of Robinow syndrome. 
Índice

Resumo

Abstract

Lista de Abreviaturas

I. Introdução

I.1 Síndrome de Robinow 1

I.2 Manifestações clínicas 2

I.3 Etiologia da Forma Autossômica Recessiva 5

I.4 Etiologia da Forma Autossômica Dominante $\quad 7$

I.5Gene DVL1 9

$\begin{array}{ll}\text { I.6 Gene DVL3 } & 10\end{array}$

I.7 Interação funcional das proteínas Wnt's 10

$\begin{array}{ll}\text { II. Objetivo } & 14\end{array}$

II.1 Objetivos específicos 14

III. Material e Métodos 15

III.1 Seleção dos pacientes $\quad 15$

$\begin{array}{ll}\text { III.2 Material biológico } & 15\end{array}$

III.3 Triagem de mutações no gene DVL1 16

III.3.1 Extração de DNA 16

$\begin{array}{lr}\text { III.3.2 PCR. } & 17\end{array}$ 
III.5 Eletroforese em gel de agarose.

III.3 Sequenciamento Sanger $\quad 18$

$\begin{array}{lr}\text { III.3.4 Clonagem } & 18\end{array}$

IV. Resultados e Discussão 18

IV.1 Descrição Clinica 18

IV.2 Diagnostico molecular $\quad 23$

V. Conclusões

VI. Referências Bibliográficas $\quad 35$

$\begin{array}{ll}\text { Anexos } & 38\end{array}$ 


\section{Índice de Figuras}

Figura 01: Ratos Wnt5a - / - têm defeitos anatômicos fenotipicamente semelhantes a pacientes com síndrome de Robinow autossômica

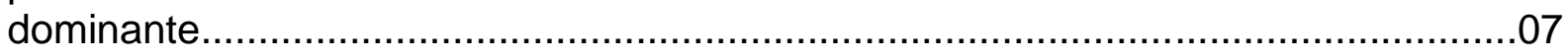

Figura 02: Rotas de sinalização celular Wnt: a canônica / â-catenina, o PCP / WNT, e as vias $\mathrm{Ca} 2+$ / WNT 12

Figura 03: Resultado do sequenciamento Sanger do paciente 01 .23

Figura 04: Resultado do sequenciamento Sanger do paciente 02 .24

Figura 05: Resultado do sequenciamento Sanger do paciente 06 .24

Figura 06: Resultado do sequenciamento Sanger do paciente 07 .25

Figura 07: Locais onde todas as variantes foram descritas na literatura atualmente no gene DVL1 da Síndrome de Robinow. .26 


\section{Índice de tabelas}

Tabela 1: Distribuição dos 75 sinais clínicos estudados com base na frequência do sinal nos afetados pela SR autossômica dominante (SRD) e SR autossômica recessiva (SRR).

Tabela 2: Primers utilizados para amplificação da região codificante do gene DVL1

Tabela 03: Mutações encontradas no presente trabalho e reportadas na literatura em pacientes com a forma autossômica dominante da síndrome de

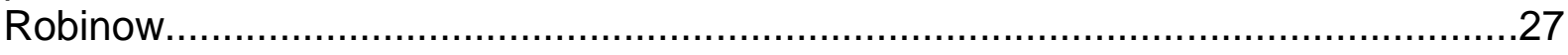

Tabela 04: Características clinicas dos pacientes investigados no presente estudo e frequência desses sinais na forma autossômica dominante da

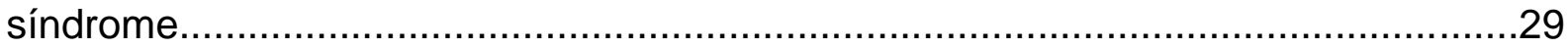




\section{Introdução}

\section{I.1 Síndrome de Robinow}

A síndrome de Robinow (SR) foi descrita pela primeira vez pelo Dr. Meinhard Robinow e cols.(1), em 1969, em uma família com afetados em pelo menos três gerações que apresentavam nanismo mesomélico, genitália hipoplásica e anomalias faciais: hipertelorismo ocular, fissuras palpebrais alargadas, nariz curto e anomalias dentárias, resultando na publicação " $A$ newly recognized dwarfing syndrome". Como foram identificados afetados em três gerações considerou-se que o padrão de herança era autossômico dominante. A síndrome é também conhecida como "Síndrome da Face Fetal", por conta das características descritas pelos autores que lembram a face de um feto de 8 semanas.

Em 1978 Wadia e cols.(2), observaram anomalias faciais e defeitos de segmentação costovertebral em dois pacientes filhos de um casal consanguíneo que apresentavam nanismo mesomélico associado a anomalias faciais e costovertebrais. Esta síndrome recebeu o acrônimo COVESDEM (costovertebral segmentation defects with mesomelia) e o mecanismo de herança era provavelmente autossômico recessivo. No ano seguinte reconheceu-se que a síndrome COVESDEM era uma variante da Síndrome de Robinow com diferente modo de herança (MIM 238310).

O primeiro caso de transmissão de pai para filho foi relatado em 1982, por Shprintzen e cols.(3), excluindo a hipótese do mecanismo de herança ligada ao X.

Devido ao pequeno número de casos descritos na literatura, ainda não é conhecida à incidência da síndrome de Robinow. Uma maior frequência da forma autossômica recessiva da síndrome foi observada em populações da Turquia e Oman, regiões que apresentam alto índice de casamentos consanguíneos; cerca de $80 \%$ dos afetados pela forma recessiva, é fruto de casamentos consanguíneos(4). A baixa incidência da síndrome pode ser atribuída também a um subdiagnóstico de muitos casos, gerados pela grande variabilidade clínica entre os pacientes, o que torna o diagnóstico clínico diferencial complexo, e reforça a necessidade de uma descrição completa do fenótipo dos afetados. 


\section{I.2 Manifestações clínicas}

As principais manifestações clínicas apresentadas pelos pacientes diagnosticados com a síndrome de Robinow são dismorfias faciais associadas a encurtamento mesomélico e genitália hipoplásica. A expressividade da síndrome é variável e o hipertelorismo ocular e a baixa estatura são os sinais mais marcantes da síndrome. A baixa estatura é mais acentuada nos indivíduos com a forma autossômica recessiva que também podem apresentar defeitos de segmentação costovertebral que incluem fusões de costela. Já os pacientes com a forma autossômica dominante, podem apresentar estatura normal e acometimento cardíaco e renal(5).

Dentro desse contexto a observação das manifestações clínicas apresentadas pelos pacientes tornou-se essencial para o diagnóstico clínico tanto para a determinação da forma de herança autossômica recessiva ou autossômica dominante quanto para o diagnóstico diferencial com síndromes que apresentam manifestações clínicas semelhantes.

Diante da dificuldade de diagnostico clinico diferencial das formas autossômica recessiva e dominante da Síndrome de Robinow, Mazzeu e col.(5) 2007 realizaram um trabalho com um protocolo para exames clínicos baseado em descrições de sinais e sintomas clínicos anteriores com uma avaliação da frequência de 75 sinais e sintomas clínicos presentes em pelo menos, $5 \%$ do total de pacientes avaliados. Foram avaliados 88 pacientes novos e da literatura sendo $37 \mathrm{com}$ SRR e $51 \mathrm{com}$ SRD. O diagnóstico baseou-se na presença de baixa estatura ou encurtamento dos membros, qualquer grau de hipoplasia genital e avaliação da face incluindo o hipertelorismo. Foram observadas as frequências de 75 sinais clínicos em pacientes com SRR e SRD e definidos aqueles que distinguiam melhor cada uma das formas da síndrome como mostra a Tabela 1. 
Tabela I: Distribuição dos 75 sinais clínicos estudados com base na frequência do sinal nos afetados pela SR autossômica dominante (SRD) e SR autossômica recessiva (SRR)(6).

\begin{tabular}{|c|c|c|}
\hline & SRD & SRR \\
\hline $75-100$ & $\begin{array}{l}\text { Hipertelorismo }(100 \%) \\
\text { Ponte nasal larga }(100,0 \%) \\
\text { Narinas antevertidas }(100,0 \%) \\
\text { Ponta do nariz voltada para cima }(86,7 \%) \\
\text { Micropênis }(84,1 \%) \\
\text { Baixa estatura }(81,2 \%) \\
\text { Nariz curto }(81,2 \%) \\
\text { Braquidactilia }(81 \%) \\
\text { Hipoplasia do macico central da face }(80,6 \%) \\
\text { Encurtamento mesomélico dos membros }(80,1 \%) \\
\text { Frontal proeminente }(79 \%) \\
\text { Ponte nasal baixa }(77,9 \%) \\
\text { Criptorquidia }(71,6 \%) \\
\text { Clinodactilia }(70 \%)\end{array}$ & $\begin{array}{l}\text { Fusão de costelas }(100 \%) \text {-critério diagnóstico } \\
\text { Hipertelorismo (100\%) } \\
\text { Ponte nasal larga }(100 \%) \\
\text { Ponta do nariz voltada para cima }(100 \%) \\
\text { Narinas antevertidas }(100 \%) \\
\text { Comissuras labiais voltadas para baixo }(100 \%) \\
\text { Hipoplasia do maciço central da face }(100 \%) \\
\text { Encurtamento mesomélico dos membros }(100 \%) \\
\text { Micropênis }(100 \%) \\
\text { Hemivértebra }(100 \%) \\
\text { Baixa estatura }(97,3 \%) \\
\text { Nariz curto }(93,2 \%) \\
\text { Braquidactilia }(91,4 \%) \\
\text { Clinodactilia }(87,8 \%) \\
\text { Boca triangular }(86,2 \%) \\
\text { Mãos pequenas }(83,9 \%) \\
\text { Hipoplasia de pequenos } 1 \text { lábios }(80,8 \%) \\
\text { Hipoplasia de clitóris (79,4\%) } \\
\text { Frontal proeminente }(77,8 \%) \\
\text { Escoliose }(77,4 \%)\end{array}$ \\
\hline $50-74$ & $\begin{array}{l}\text { Boca triangular }(64,9 \%) \\
\text { Filtro longo }(64,7 \%) \\
\text { Macrocefalia }(64,2 \%) \\
\text { Comissuras labiais voltadas para baixo }(62,9 \%) \\
\text { Mãos pequenas }(61,5 \%) \\
\text { Micrognatia }(56,7 \%) \\
\text { Cílios longos }(54 \%) \\
\text { Palato alto }(51,5 \%) \\
\text { Hipoplasia de pequenos lábios }(50,4 \%)\end{array}$ & $\begin{array}{l}\text { Má oclusão dentária }(74,6 \%) \\
\text { Hiperplasia de gengiva }(71,0 \%) \\
\text { Micrognatia }(68,2 \%) \\
\text { Criptorquidia }(66,7 \%) \\
\text { Cílios longos }(58,8 \%) \\
\text { Língua bífida }(58,8 \%)\end{array}$ \\
\hline $25-49$ & $\begin{array}{l}\text { Lábio superior fino }(49,6 \%) \\
\text { Fissuras palpebrais alargadas }(49,5 \%) \\
\text { Má oclusão dentária }(49,4 \%) \\
\text { Palato estreito }(45,9 \%) \\
\text { Hipoplasia de clitóris }(45,9 \%) \\
\text { Retrognatia }(44 \%) \\
\text { Pectus excavatum }(44 \%) \\
\text { Epicanto }(39,1 \%) \\
\text { Língua bifida }(38,5 \%) \\
\text { Inclinaçao mongolóide das fissuras palpebrais }(37,2 \%) \\
\text { Olhos proeminentes }(36,6 \%) \\
\text { Hiperplasia de gengiva }(35,8 \%) \\
\text { Polegares alargados }(35,6 \%)\end{array}$ & $\begin{array}{l}\text { Ponte nasal baixa }(48,7 \%) \\
\text { Orelhas de implantação baixa }(44,9 \%) \\
\text { Hipoplasia de grandes lábios }(39,8 \%) \\
\text { Filtro longo }(38,9 \%) \\
\text { Retrognatia }(36,6 \%) \\
\text { Limitação do movimento de supinação dos cotovelos } \\
\text { (36,5\%) } \\
\text { Displasia de unhas }(35 \%) \\
\text { Fissuras palpebrais alargadas }(33,9 \%) \\
\text { Pescoço curto }(30,7 \%) \\
\text { Pectus excavatum }(30,6 \%) \\
\text { Polegares alargados }(30,6 \%) \\
\text { Lábio superior fino }(29 \%)\end{array}$ \\
\hline
\end{tabular}




\begin{tabular}{|c|c|c|}
\hline & $\begin{array}{l}\text { Encurtamento rizomélico dos membros }(35,4 \%) \\
\text { Hipoplasia de grandes lábios }(34,9 \%) \\
\text { Fenda labial/palatina }(34,7 \%) \\
\text { Hálux alargado }(33,1 \%) \\
\text { Hérnia umbilical }(32,3 \%) \\
\text { Pescoço curto }(29,4 \%) \\
\text { Problemas cardíacos (exceto sopro) }(28,6 \%) \\
\text { Orelhas de implantação baixa }(28,1 \%) \\
\text { Anomalias renais }(26,5 \%) \\
\text { Infecções respiratórias recorrentes }(25,2 \%)\end{array}$ & Macrocefalia $(25,5 \%)$ \\
\hline & $\overline{\text { SRD }}$ & $\overline{\text { SRR }}$ \\
\hline $10-25$ & $\begin{array}{l}\text { Hemivértebra }(22,7 \%) \\
\text { Displasia de unhas }(21,7 \%) \\
\text { Retardo mental/ RDNPM }(20,5 \%) \\
\text { Nevo facial }(19,4 \%) \\
\text { Escoliose }(17,6 \%) \\
\text { Escleróticas azuladas }(17,3 \%) \\
\text { Hérnia inguinal }(16,9 \%) \\
\text { Filtro curto }(16,8 \%) \\
\text { Lábio superior em forma de arco de cupido }(16,7 \%) \\
\text { Dentes infranumerários }(15,8 \%) \\
\text { Fosseta sacral }(14,9 \%) \text { ) } \\
\text { Inclinaça antimongolóide das fissuras palpebrais }(14,6 \%) \\
\text { Aumento da distância entre } \circ 1 \circ \text { e } 2 \circ \text { artelhos }(14,6 \%) \\
\text { Ptose palpebral (14,5\%) } \\
\text { Prega palmar transversal única }(14,5 \%) \\
\text { Calvície frontal }(14,4 \%) \\
\text { Orelhas pequenas }(14,4 \%) \\
\text { Sindactilia }(14,4 \%) \\
\text { Sopro cardíaco (14,4\%) } \\
\text { Estrabismo }(12.2 \%) \\
\text { Surdez (11,9\%) } \\
\text { Dentes supranumerários }(10,3 \%)\end{array}$ & $\begin{array}{l}\text { Hálux alargado }(24,2 \%) \\
\text { Nevo facial }(23,9 \%) \\
\text { Hérnia inguinal }(21,3 \%) \\
\text { Sopro cardiaco }(20,7 \%) \\
\text { Dentes infranumerários }(18,3 \%) \\
\text { Infecçós respiratórias recorrentes }(18,3 \%) \\
\text { Sindactilia }(17,9 \%) \\
\text { Camptodactilia }(17,4 \%) \\
\text { Inclinação mongolóide das fissuras palpebrais }(14,5 \%) \\
\text { Orelhas pequenas }(13,8 \%) \\
\text { Palato alto }(13,7 \%) \\
\text { Palato estreito }(13,7 \%) \\
\text { Prega palmar transversal única }(13,7 \%) \\
\text { Fosseta sacral }(13,7 \%) \\
\text { Luxação congênita do quadril }(13,7 \%) \\
\text { Ptose palpebral }(13,6 \%) \\
\text { Filtro curto }(13,6 \%) \\
\text { Olhos proeminentes }(13,5 \%) \\
\text { Fenda labial/palatina }(13,5 \%) \\
\text { Problemas cardíacos (exceto sopro) }(13,5 \%) \\
\text { Hipospadia }(12,5 \%) \\
\text { Epicanto }(10 \%) \\
\text { Estrabismo }(10 \%) \\
\text { Anomalias renais }(10 \%) \\
\text { Anus anteriorizado }(10 \%) \\
\text { Surdez (10\%) }\end{array}$ \\
\hline$<10$ & $\begin{array}{l}\text { Orelhas simplificadas }(9,5 \%) \\
\text { Luxação congênita de quadril }(9,4 \%) \\
\text { Hipospadia }(8,8 \%) \\
\text { Pectus carinatum }(7,2 \%) \\
\text { Limitação do movimento de supinação dos cotovelos }(7,0 \%) \\
\text { Anus anteriorizado }(7,0 \%) \\
\text { Camptodactilia }(4,8 \%)\end{array}$ & $\begin{array}{l}\text { Retardo mental }(7,4 \%) \\
\text { Calvície frontal }(6,6 \%) \\
\text { Lábio superior em forma de arco de cupido }(6,6 \%) \\
\text { Encurtamento rizomélico dos membros }(6,6 \%) \\
\text { Inclinação antimongolóide das fissuras palpebrais } \\
(6,5 \%) \\
\text { Aumento da distância entre } 1 \circ \text { e } 2 \circ \text { artelhos }(6,5 \%) \\
\text { Escleróticas azuladas }(3,2 \%) \\
\text { Pectus carinatum }(3,2 \%) \\
\text { Orelhas simplificadas }(3,1 \%) \\
\text { Dentes supranumerários }(0 \%) \\
\text { Hérnia umbilical }(0 \%)\end{array}$ \\
\hline
\end{tabular}


Hoje o diagnóstico diferencial das formas da Síndrome de Robinow está bem descrito quando se avalia um grupo de informações obtidas como histórico familiar, apresentação dos sinais clínicos, seu enquadramento dentro do grupo de sinais clínicos já observados para cada variante da síndrome e técnicas moleculares de diagnóstico que atualmente são uma ferramenta indispensável para confirmação da suspeita clínica.

Os principais sinais clínicos da forma autossômica recessiva da SR incluem baixa estatura pronunciada, encurtamento mesomélico de membros, fusão de costelas, braquidactilia, hipoplasia genital e dismorfias faciais. As dismorfias faciais incluem testa proeminente, hipertelorismo ocular, hipoplasia facial, boca larga e nariz curto com narinas antevertidas(5). As anomalias orais incluem hipertrofia da gengiva, anormalidades dentárias e fenda lábio palatina.

O diagnóstico clínico diferencial entre a síndrome de Robinow e outras síndromes como as de Langer, Leri-Weill (com baixa estatura e encurtamento de membros), Aarskog e Opitz (com hipoplasia facial e deformidades genitais), ainda pode ser difícil visto que algumas apresentam encurtamento de membros e baixa estatura associada à hipoplasia genital, alterações clínicas semelhantes às que acometem os pacientes afetados pela síndrome de Robinow(7).

\section{I.3 Etiologia da Forma Autossômica Recessiva (SRR [MIM 268310]).}

Por ser uma displasia esquelética grave que promove anomalias esqueléticas acentuadas que levam ao acometimento da estrutura óssea de seus afetados a forma autossômica recessiva da síndrome de Robinow tem instigado pesquisadores a buscarem a melhor compreensão dos mecanismos envolvidos na etiologia da síndrome. Na busca da causa genética da síndrome Afzal e cols(8) em 2000, realizaram o mapeamento por homozigose para identificar o gene envolvido na síndrome de Robinow autossômica recessiva, por meio de uma ampla pesquisa do genoma envolvendo cinco famílias de casais consanguíneos e descendentes afetados pela síndrome de Robinow autossômica recessiva. A única região de homozigose comum ocorreu em um segmento de 3-4 CM na região 9q22, entre os marcadores D9S1836 e D9S1803. 
Os mesmos autores deram continuidade ao estudo para localizar o gene no intervalo identificado, a partir da análise de polimorfismo conformacional de fita simples (SSCP) e sequenciamento e identificaram mutações nos exons 5,7 e 9 do gene ROR2 em 26 dos 27 pacientes investigados. Simultaneamente, Van Bokhoven e cols(9) 2000, encontraram mutações nos exons 5, 8 e 9 por sequenciamento em onze famílias com afetados pela SRR.

Em 2004, Schwabe e cols(10), realizaram um trabalho em modelo animal apresentando uma detalhada análise de camundongos nocaute Ror2 - 1 . comparando com o desenvolvimento dos sinais clínicos apresentados por afetados pela forma recessiva da síndrome de Robinow. Análise da expressão de Ror2 na região craniofacial foi realizada em embriões em diferentes fases de desenvolvimento, onde encontraram diversas alterações ósseas.

O estudo em modelo animal ressalta a importância da expressão do gene Ror2 nas fases iniciais da embriogenese, sua influência na formação óssea e a atividade das proteínas Wnts durante o processo. Esses achados sugerem a possível interação entre Wnts e Ror2 e sua interferência no desenvolvimento das manifestações clínicas apresentadas por afetados pela forma autossômica recessiva da síndrome de Robinow e fornecem evidências para a melhor compreensão dos processos intracelulares que desencadeiam a clínica dos afetados(10).

\section{4 Etiologia da Forma Autossômica Dominante}

Assim como nos camundongos com mutação no gene Ror2, foi observado que camundongos nulos para Wnt5a exibiam fenótipos semelhantes aos encontrados em pacientes com síndrome de Robinow, incluindo dismorfismo facial, hipoplasia genital, encurtamento de membros e defeitos cardíacos e ainda, que a sinalização não canônica de Wnt que regulava a direção de migração celular era necessária para fusão do palato secundário durante o desenvolvimento embrionário $(11,12)$. 

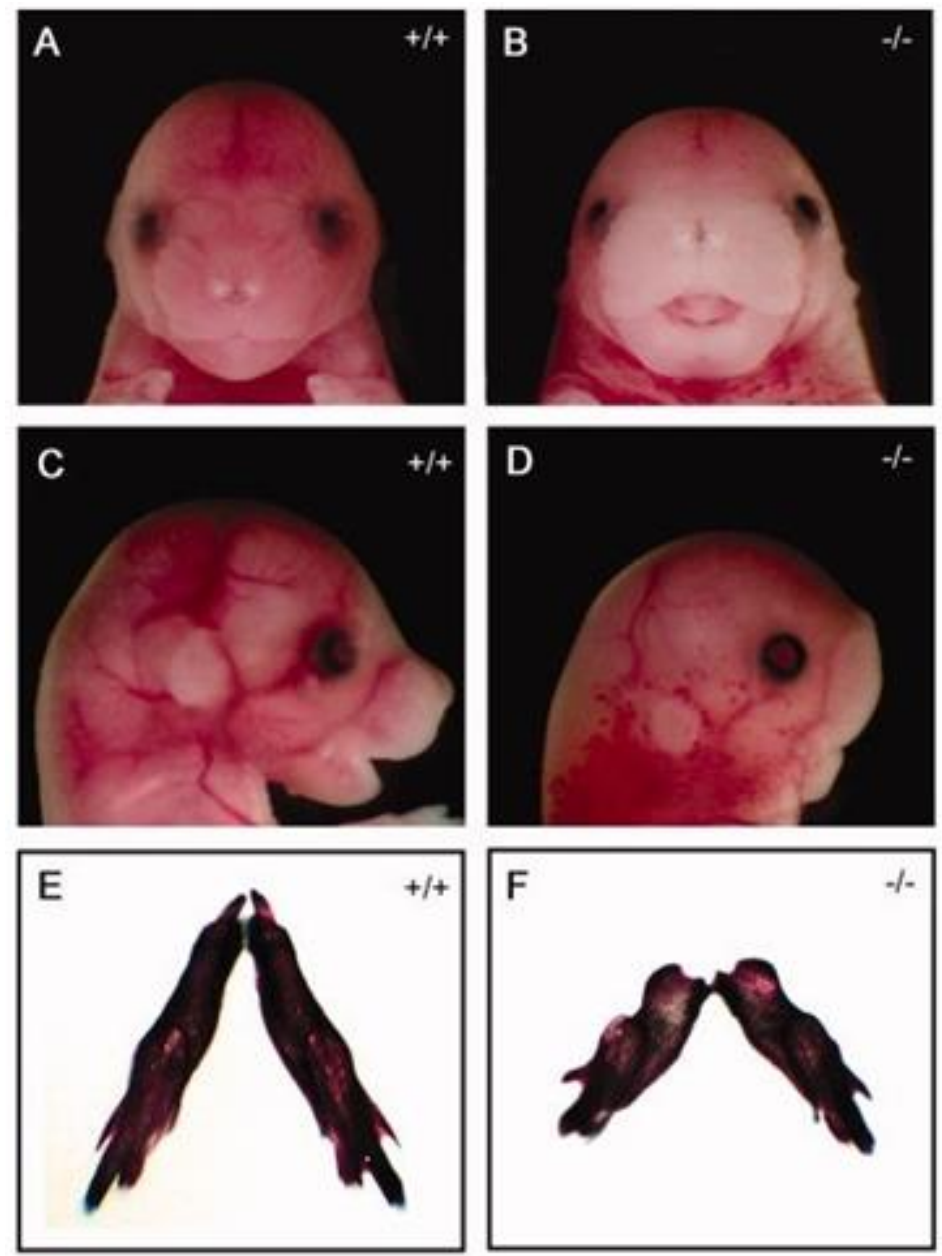

\begin{tabular}{|c|c|c|}
\hline Caracteristicas & DRS $^{e}$ & $\mathrm{Wnt5a}^{+}$mice \\
\hline Hipertelorismo & $100 \%$ & $t^{2}$ \\
\hline Genitália hipoplásica (micropênis) & $84 \%$ & + \\
\hline Baixa estatura & $81 \%$ & $+b$ \\
\hline Braquidactilia & $81 \%$ & $++^{b}$ \\
\hline Nariz curto & $81 \%$ & $++^{a}$ \\
\hline Encurtamento de membro mesomelico & $80 \%$ & $t^{\mathrm{b}}$ \\
\hline Boca triangular & $65 \%$ & $+t^{a}$ \\
\hline Micrognatia & $57 \%$ & +2.6 \\
\hline Encurtamento de membro rizomelico & $35 \%$ & $+^{b}$ \\
\hline Fenda labial/palatina & $35 \%$ & $+1-^{\mathrm{c}}$ \\
\hline Defeitos cardíacos & $29 \%$ & $+^{d}$ \\
\hline Baixa implantaç3o das orelhas & $28 \%$ & $+^{*}$ \\
\hline Orelhas pequenas & $14 \%$ & $++^{2}$ \\
\hline
\end{tabular}

Figura 01 - Camundongos Wnt5a-1- têm defeitos anatômicos fenotipicamente semelhantes a pacientes com síndrome Robinow autossômica dominante. A, B: Wnt5a-1- embriões de camundongos no dia embrionário (E) 16,5 (B) têm olhos amplamente espaçados (hipertelorismo) e uma boca triangular em comparação com os controles (A). C, D: Vistas laterais revelam achatamento do perfil facial, micrognatia, e orelhas pequenas e baixas nos $W n t 5 a^{-1}$ embriões (D) em comparação com irmãos controle (C). E, F: preparações esqueléticas no nascimento mostram hipoplasia mandibular em Wnt5a mutantes $(F)$, em comparação com os controles (E). G: Porcentagem de resultados relatados em pacientes com síndrome Robinow dominante comparação com fenótipos em camundongos Wnt5a-1.(13). 
A partir dos resultados obtidos em modelo animal foi sugerido que as alterações no gene WNT5A poderiam estar envolvidas com o fenótipo apresentado pelos pacientes com a síndrome de Robinow. Buscando a confirmação dessa possível relação, em 2010 Person e cols.(13), realizam um estudo com pacientes diagnosticados com a forma autossômica dominante da síndrome e identificaram mutações no gene WNT5A em 12\% dos pacientes investigados, inclusive na família originalmente descrita por Robinow e cols. em 1969, confirmando o papel do gene WNT5A na etiologia da síndrome.

Outras três famílias com mutação em WNT5A foram descritas por Roifman e cols(14). em 2014. Em uma das famílias a mutação foi identificada por sequenciamento de exoma e a mutação confirmada por sequenciamento Sanger.

O gene WNT5A está localizado no braço curto do cromossomo 3, 3p21-p14, nas posições $\quad 55.465 .714$ - 55.505 .260 pb. Faz parte da família dos genes $W N T$, que codificam proteínas de sinalização com atividade de regulação dos eventos morfogênicos, padronização durante a embriogênese, diferenciação celular, crescimento, migração e oncogênese(12).

Sua atividade de sinalização intracelular ocorre a partir do complexo receptorligante com os receptores FZD5 (frizzled-5) e ROR2 (receptor órfão com atividade tirosina quinase 2). O receptor ROR2 está envolvido com o fenótipo encontrado em pacientes na forma autossômica recessiva, as proteínas Wnt ligam-se diretamente no domínio rico em cisteína extracelular do receptor ROR2; essa interação entre o receptor e as proteínas Wnt desencadeia uma das vias de transdução de sinal que tem atividade no desenvolvimento craniofacial e esqueleto.

Apesar da interação clara entre WNT5A e ROR2 apenas cerca de $12 \%$ dos indivíduos com a forma autossômica dominante da síndrome de Robinow tem mutação no gene WNT5A, sugerindo que outros genes da via estejam envolvidos na etiologia da síndrome. 


\section{5 Gene DVL1}

White e cols. e Bunn e cols (2015), relataram oito e três pacientes respectivamente com a forma autossômica dominante da síndrome com mutações em DVL1 (dishevelled segment polarity protein 1), um gene que codifica um dos três ortólogos humanos da proteína da Dishevelled da Drosophila (DSH). DVL1 está localizado no braço curto do cromossomo 1, 1p36.33, que codifica uma fosfoproteína citoplasmática que regula a proliferação celular, atuando em processos de desenvolvimento, incluindo a segmentação e especificação de neuroblastos. Gene DVL1 possui cerca de $13.84 \mathrm{~kb}$ e compreende 15 exons. Todas as variantes patogênicas relatadas são mutações no exon 14, provavelmente levando a uma transcrição truncada(15,16). A identificação de mutações nesse gene apoia o conceito de que mutações em outros genes da via WNT5A-ROR2 podem causar a Síndrome de Robinow.

Estudos recentes sugerem que os três homólogos humanos DVL1, DVL2, e DVL3, são componentes fundamentais no encaminhamento correto de transmissão de sinais de Wnt canônicos e não canônicos, a maioria provavelmente por agir em grandes complexos multiproteicos. Coletivamente, a síndrome de Robinow parece ser um resultado da desregulação da via WNT5A-ROR2-DVL(16).

Quanto à observação das manifestações clínicas, o fenótipo dos indivíduos com mutações DVL1 é concordante com as descrições clínicas anteriores como características faciais típicas, anomalias dentárias e mesomelia observadas em $100 \%$ dos indivíduos. Em contraste com os indivíduos com mutações WNT5A relatados até o momento com estatura normal e apenas $75 \%$ dos indivíduos com mutações em DVL1 apresentaram essa característica. Outro diferencial possível entre os dois tipos de DRS é macrocefalia observada em 100\% dos indivíduos com mutações em DVL1. Em três pacientes com mutação em DVL1 foi observada osteoesclerose $(15,16)$.

Estudos complementares são necessários para investigar se mutações no exon 14 do gene $D V L 1$ têm uma atividade residual que compete com a proteína selvagem e sua função ou se o domínio C-terminal realiza um novo papel biológico imprevisível. O ganho de função da proteína mutante está previsto para contribuir para a doença dominante. Mutações que geram perda de função observadas em 
camundongos nocaute para o gene $D v / 1$, originam um fenótipo relativamente leve consistindo de problemas comportamentais e contrastam com os defeitos morfológicos graves observados em camundongos nocaute com mutações em Wnt5a ou Ror2. Estas observações em camundongos suportam a hipótese de que o DVL1 truncado em indivíduos com DRS não levam ao fenótipo por perda de função, mas, sim pelo ganho de função.

\section{I-6 Gene DVL3}

O gene DVL3 (Dishevelled Segment Polarity Protein 3) codifica a proteína de mesmo nome está localizado no braço longo do cromossomo 3, 3q27.1 e compreende 19 exons Codifica uma fosfoproteína citoplasmática que regula a proliferação celular, possui 716 aminoácidos.

White e colaboradores sugeriram que mutações nos homólogos de DVL1; DVL2 (MIM: 602151), e DVL3 (MIM: 601368), pudessem causar a forma autossômica da síndrome quando mutados. Esses autores identificaram mutações em DVL3 em quatro afetados pela síndrome(17). Mutações em DVL2 não foram identificadas até o momento.

Devido à localização uniforme de variantes associadas à síndrome de Robinow mediada por DVL1, e o conhecimento que DVL1, DVL2 e DVL3 compartilham de $59 \%$ a $67 \%$ de homologia de aminoácidos, todas as variantes em DVL3 resultam em mudança no quadro de leitura, o que indica que estas alterações altamente especificas podem ser uma causa comum da síndrome Robinow dominante(16).

\section{I-7 Interação funcional das proteínas WNTs}

As proteínas Whts tem um potencial grande em diversos tipos de processos de sinalização que estão ligadas e podem interferir no desenvolvimento, formação do eixo embrionário primário, e também trazer consequências patológicas como o melanoma e doenças neurodegenerativas(18). A cascata de sinalização Wnts abrange vários componentes e também é bastante complexa, sendo composta de 
três vias principais: - canônica, polaridade celular planar e cálcio dependente (Figura 2).

Os receptores que realizam as interações com as proteínas Wnts, que são Frizzled (Fz), receptor de lipoproteína 6 (LRP6), ROR2, proteína Tyr quinase 7 (PTK7), receptor de quinase Tyr (RYK), cada receptor atuando em uma via de sinalização diferente(19).

A sinalização Wnt canônica é ativada quando se liga a um complexo receptor composto de $\mathrm{Fz}$ e proteínas relacionadas com o receptor e co-receptores de lipoproteína de baixa densidade 5/6 (Lrp5/6) formando uma estrutura dimérica/ multimérica. Isto desencadeia uma fosforilação de Lrp5/6 por CK1 e GSK3-â levando a associação de GSK3 com proteínas Axin. Por outro lado, Fz interage com Dishevelled (Dvl)(20,21), que por sua vez promove a interação com Axin(22,23). Estes eventos em conjunto, fazem com que a â-catenina acumulada no citoplasma seja translocada para o núcleo, onde se associa com fatores de transcrição, tais como TCF (fator de célula T) e LEF (fator potenciador linfóide de ligação) para mediar a transcrição indução de genes-alvo. 


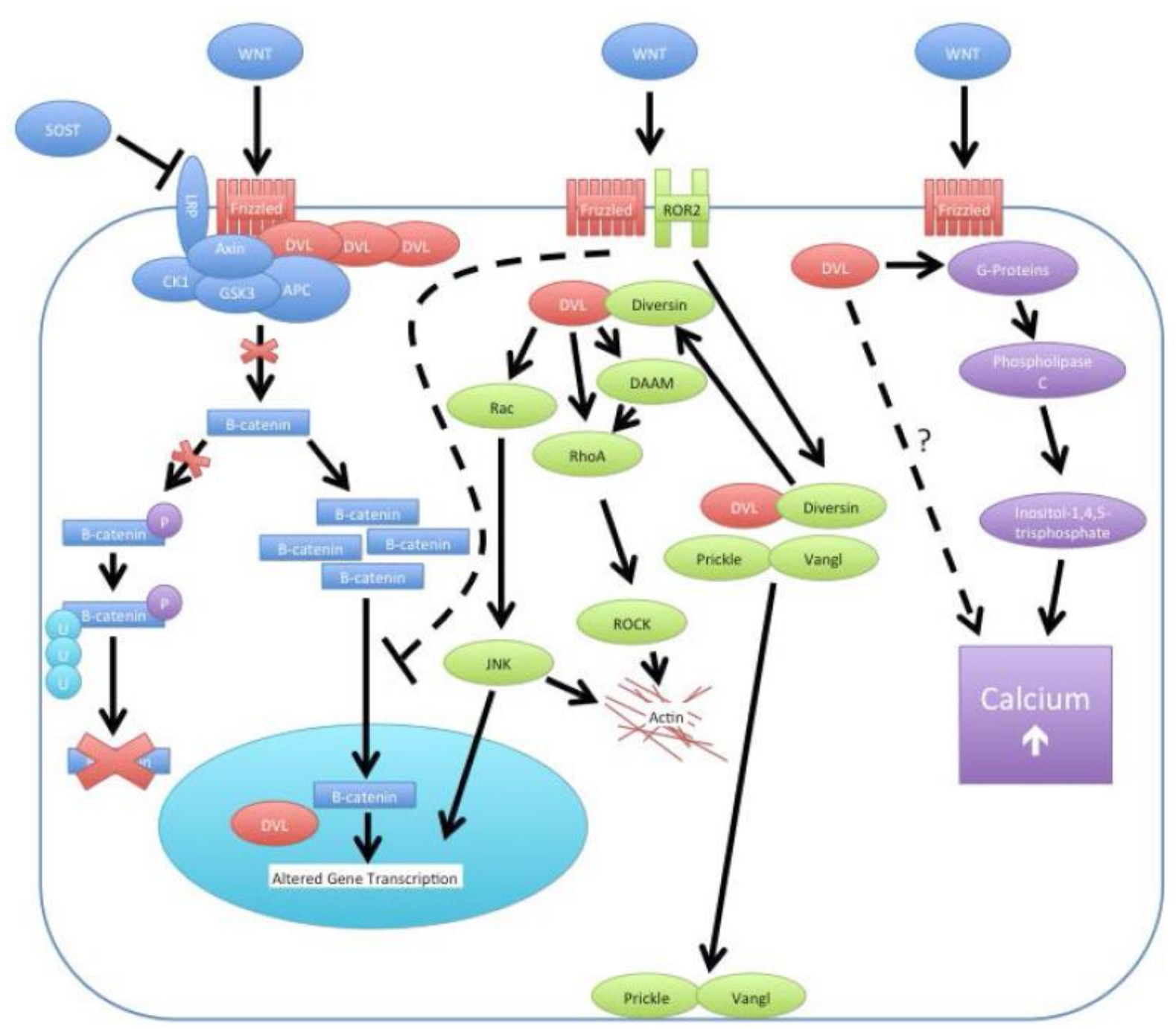

Figura 02: Esta ilustração descreve as rotas mais elucidadas de sinalização celular Wnt, que são da esquerda para a direita: a canônica / â-catenina, o PCP / WNT, e as vias Ca2 + / WNT. DVL está marcado em vermelho. O mecanismo pelo qual o PCP inibe a via canônica é desconhecido (15). 
A literatura mostra 19 genes existentes que codificam Wnts que ativam duas diferentes vias de sinalização, que são nomeadas de canônica (â-cateninadependente) ou não-canônica (â-catenina independente). Uma das vias independentes de â-catenina é a via de PCP (polaridade celular planar), mediada por receptores ROR2 que realizam interação com as proteínas Wnts desencadeando processos de transcrição. O funcionamento dessa via é fundamental na osteoblastogênese e osteoclastogênese, mostrando que qualquer interferência na atuação do receptor ROR2, influencia no desenvolvimento do esqueleto, como evidenciado nos pacientes com a síndrome de Robinow.

A busca sobre o conhecimento de novas mutações em genes dessa via, associado ao fenótipo dos pacientes, podem colaborar para um maior entendimento de seus processos biológicos, como também ajudar no diagnostico molecular de pacientes com SR, correlacionando o genótipo e o fenótipo dos indivíduos, levando a um melhor entendimento da fisiopatologia de cada uma das formas da síndrome, como também enriquecer a literatura dos mecanismos de ação do gene DVL1. 


\section{Objetivo geral}

O objetivo geral desse trabalho foi identificar novas mutações no gene DVL1 em pacientes com a Síndrome de Robinow autossômica dominante.

\section{II.1 Objetivos Específicos}

1. Descrever o quadro clínico dos pacientes a fim de corroborar a hipótese diagnóstica da forma autossômica dominante da síndrome.

2. Pesquisar mutações no gene $D V L 1$ em afetados pela forma dominante da SR buscando a caracterização de novas mutações.

3. Verificar se há correlação entre o fenótipo e o tipo de mutação identificada. 


\section{Materiais e Métodos}

\section{III.1 Seleção dos pacientes para estudo}

1. Foram selecionados 11 pacientes com características clínicas da Síndrome de Robinow autossômica dominante que aceitaram participar da pesquisa.

2. Os pacientes foram encaminhados pela Robinow Syndrome Foundation, EUA.

3. Os pacientes ou genitores preencheram termo de consentimento livre e esclarecido.

4. O projeto foi aprovado pelo comitê de ética em pesquisa da Faculdade de Medicina da Universidade de Brasília (CEP FM: 079/2009; 25/11/2009).

Os pacientes foram avaliados pela Profa Dra Juliana Forte Mazzeu de Araújo durante os encontros da Robinow Syndrome Foundation com base na anamnese, exame físico e dados de prontuários médicos com exceção do paciente 2. Para todos foi preenchida uma ficha para anotação dos dados de anamnese, da qual constam os principais sinais clínicos a serem investigados em pacientes com a síndrome (Anexo II).

Os pacientes 1, 2, 3, 5, 8, 9 e 10 não apresentam mutação nos genes WNT5A e ROR2.

\section{III.2 Material biológico}

As amostras de sangue foram obtidas por punção venosa, em tubos de coleta com sistema a vácuo e EDTA como anticoagulante. Os voluntários maiores de 18 anos assinaram o termo de consentimento livre e esclarecido, os pacientes 
menores de idade tiveram o consentimento livre e esclarecido assinado pelos responsáveis.

\section{III.3 Triagem de mutações no gene DVL1.}

A pesquisa de mutações no gene foi realizada por sequenciamento Sanger direto em DVL1.

\section{III.3.1 Extração de DNA}

A extração de DNA foi feita a partir do sangue periférico pelo método Puregene "Salting out". Este método é dividido em etapas, sendo a primeira de lise celular, onde foi utilizado $5 \mathrm{mM} \mathrm{MgCl} 2,1 \mathrm{mM}$ EDTA pH 8,0 em uma reação e, $10 \mathrm{mM}$ Tris pH 7,5, 1mM EDTA pH 8,0 e 1\% SDS em outra, para cada reação a solução foi centrifugada a $3400 \mathrm{rpm}$ por 10 minutos. Para a segunda etapa utilizou-se $1 \mathrm{ml}$ da solução de precipitação de proteína ao lisado celular. Esta solução contém 7,5M de NH4 Ac. Centrifugou-se a 3400 rpm por 10 minutos. As proteínas precipitadas formam um pellet marrom escuro e compacto.

$\mathrm{Na}$ etapa de precipitação de DNA, o sobrenadante foi transferido para um tubo Falcon contendo $3 \mathrm{ml}$ de isopropanol. $\mathrm{O}$ tubo foi invertido lentamente até que se formasse um novelo de DNA. A reação foi centrifugada a 3400 rpm por 3 minutos. Retirou-se o sobrenadante, e adicionou-se $3 \mathrm{ml}$ de etanol absoluto. A reação foi novamente centrifugada. Depois disso, drenou-se o tubo e deixou-se o DNA secar a temperatura ambiente por 15 minutos. Na última etapa, acrescentou-se ao tubo com - DNA, 200-250 $\mu \mathrm{l}$ de TE 1x ou água milliQ, que resultou em uma concentração aproximada de $400 \mathrm{ng} / \mu \mathrm{l}$. O DNA foi armazenado a 2-8ㅇ.

O DNA obtido foi quantificado no espectrofotômetro Nanodrop (Thermo Scientific) 


\section{III.3.2 PCR- Reação em cadeia pela polimerase}

Para as reações de PCR, num volume total de 25I, foram utilizados 80-200ng de DNA genômico, 2,5l de dNTP (200M de dCTP, dTTP, dGTP e dATP); 2,5U da enzima Taq polimerase (Invitrogen, Carlsbad, USA) e 2,5I de tampão específico dessa enzima; $\mathrm{MgCl} 2$ em concentração otimizada para cada par de primer, 11 $(1,5 \mathrm{M})$, de pares de primers específicos na tabela 1 e quantidade complementar de água. As condições de amplificação foram as seguintes: cinco minutos de desnaturação inicial a $94^{\circ} \mathrm{C}, 35$ ciclos de um minuto a $94^{\circ} \mathrm{C}$, um minuto à temperatura de annealing calculada para cada par de primer e um minuto a $72^{\circ} \mathrm{C}$, seguidos de uma etapa de extensão de 10 minutos a $72^{\circ} \mathrm{C}$.

Tabela 2: Primers utilizados para amplificação da região codificante do gene DVL1. Cada par de primer amplifica um exon do gene DVL1 ou parte dele.

\begin{tabular}{cc}
\hline Exon & Sequência \\
\hline $14 F$ & $5^{\prime}-$ CAAGATCACCTTCTCCGAGC - 3' \\
$14 R$ & $5^{\prime}-$ GCCCAAGTACACAGCAGGAG - 3' \\
$15 F$ & $5^{\prime}-$ CTCAAGCATCGGGGTGAG - 3' \\
$15 R$ & $5^{\prime}-$ GACACAGGTGCTGTCAGGAG - 3' \\
\hline
\end{tabular}

\section{3.3 Sequenciamento Sanger}

A purificação das amostras para sequenciamento foi realizada com kit Illustra ${ }^{\mathrm{TM}}$ ExoProStar $^{\mathrm{TM}}$. 
O sequenciamento Sanger foi realizado para 11 pacientes participantes da pesquisa. Para o sequenciamento Sanger foi utilizado o sequenciador ABI 3130 da Applied Biosystems, no Laboratório de Biotecnologia do Programa de Pósgraduação em Ciências Genômicas e Biotecnologia da Universidade Católica de Brasília, seguindo o protocolo de sequenciamento de rotina do laboratório. Como as principais mutações dos pacientes se dão por mudança do quadro de leitura (Frameshift), o que requer uma maior qualidade no sequenciamento, os resultados obtidos não foram satisfatórios, e foram refeitos no Baylor Hopkins Center for Mendelian Genomics (Houston, TX, EUA) em parceria já estabelecida.

\section{III.3.4 Clonagem}

Os fragmentos de PCR foram clonados utilizando o TOPO TA cloning kit (Thermo Fisher, Carlsbad, EUA) e posteriormente sequenciados por sequenciamento Sanger.

\section{Resultados e Discussão}

Foram avaliados 11 pacientes com diagnóstico da forma autossômica dominante da síndrome de Robinow sendo que quatro apresentaram mutações em heterozigose no exon 14 do gene DVL1.

\section{IV.1 Descrição Clínica}

\section{Paciente 1}

Paciente do sexo masculino com quarenta e nove anos de idade, nascido nos Estados Unidos, filho de pais não consanguíneos. Nasceu de parto normal, medindo $46 \mathrm{~cm}\left(<3^{\circ}\right.$ percentil) e pesando $2,5 \mathrm{~kg}\left(<3^{\circ}\right.$ percentil). Foi diagnosticado com a síndrome aos sete anos de idade. Fez cirurgia para aproximar os olhos e fechar 0 
palato. Ao exame clinico observou-se estatura normal $\left(1,69 \mathrm{~m}\right.$; entre o $10^{\circ}$ e $25^{\circ}$ percentis) macrocefalia ( $P C=62 \mathrm{~cm}$, > percentil 98 ), cabelo esparso, calvície frontal, frontal proeminente, hipertelorismo, fissuras palpebrais alargadas, fácies achatado, nariz curto, narinas antevertidas, boca triangular, lábio superior fino, má implantação dentária, hipodontia, orelhas simplificadas e longas, encurtamento mesomélico de membros, hiperextensibilidade articular, clinodactilia de $5^{\text {os }}$ dedos, braquidactilia, genitália hipoplásica com micropenis e criptorquidia bilateral e encurtamento de pododáctilos. Refere múltiplas infecções renais.

\section{Paciente 2}

Paciente do sexo masculino com 45 anos de idade, nascido na Argentina, filho de pais não consanguíneos. Ao exame clinico observou-se estatura normal abaixo do canal familiar, macrocefalia, hipertelorismo, testa larga e proeminente, nariz curto, ponte nasal larga, língua encurtada, fenda labial, hipertrofia de gengiva, apinhamento dentário, dentes irregulares, micrognatia, encurtamento mesomélico discreto, braquidactilia, genitália hipoplásica, criptorquidia, escoliose discreta. Relata infecções de ouvido frequentes na infância, perda de audição, problemas respiratórios e refluxo gastroesofágico.

\section{Paciente 3}

Paciente do sexo masculino atualmente com 18 anos de idade, nascido nos Estados Unidos, filho de pais não consanguíneos. Ao exame físico apresenta baixa estatura, fácies típica com hipertelorismo, epicanto, nariz curto, hipertrofia de gengivas, fenda labial, bilateral, lóbulos da orelha espessos, encurtamento mesomélico de membros, hipertelorismo mamilar, micropênis e criptorquidia à direita (corrigida). 


\section{Paciente 4}

Paciente do sexo feminino com 20 anos de idade, nascida nos Estados Unidos, filha de pais não consanguíneos. Ao exame físico apresenta baixa estatura $\left(1,50 \mathrm{~m} ;\right.$, $3^{\circ}$ percentil), macrocefalia $\mathrm{PC}=59 \mathrm{~cm},>98^{\circ}$ percentil), olhos proeminentes, hipertelorismo, epicanto, cílios longos, ponte nasal larga, narinas antevertidas, nariz bulboso, filtro curto, boca em arco de cupido, palato alto, língua bífida, microretrognatia, encurtamento mesomélico de membros, clinodactilia, braquidactilia e polegares alargados.

\section{Paciente 5}

Paciente do sexo masculino com 16 anos de idade, nascido no Canadá, filho de pais não consanguíneos. Ao exame clinico observou-se baixa estatura, bossa frontal, hipertelorismo, estrabismo, cílios longos, ponte nasal larga, narinas antevertidas, boca triangular, lábio superior fino, hipoplasia maxilar, nevo facial, microretrognatia, braquidactilia, polegares alargados, micropênis, criptorquidia e hérnia umbilical.

\section{Paciente 6}

Paciente do sexo masculino com 19 anos de idade, nascido nos Estados Unidos, filho de pais não consanguíneos. Ao exame clinico observou-se estatura normal macrocefalia (PC; 70,5cm. > percentil 98), bossa frontal, olhos proeminentes, nariz bulboso, narinas antevertidas, ponte nasal larga, filtro longo, boca triangular, cantos da boca voltados para baixo, lábio superior fino, palato alto, hiperplasia gengival, língua bífida, anormalidades dentárias, genitália hipoplásica e ambígua, fosseta sacral e hérnia umbilical. 


\section{Paciente 7}

Paciente do sexo feminino com 31 anos de idade, nascida na Inglaterra, filha de pais não consanguíneos. Ao exame clinico observou-se estatura limítrofe $\left(1,52\right.$, entre $3^{\circ} \mathrm{e}$ 5 o percentis), macrocefalia ( $\mathrm{PC}=59 \mathrm{~cm},>98^{\circ}$ percentil), olhos proeminentes, nariz bulboso, narinas antevertidas, ponte nasal larga, filtro longo, boca em forma de triangulo, língua bífida, micrognatia, hiperplasia gengival, displasia mesomelica, braquidactilia e hérnia umbilical. Apresentava Tetralogia de Fallot.

\section{Paciente 8}

Paciente do sexo masculino com 30 anos de idade, nascido nos Estados Unidos, adotado, pais biológicos desconhecidos. Nasceu com múltiplas malformações e dismorfias dentre elas: baixa estatura $\left(1,55 \mathrm{~m},<3^{\circ}\right.$ percentil), macrocefalia, testa alta, hipoplasia de face média, hipertelorismo, fendas palpebrais amplas, narinas antevertidas, hiperplasia gengival, língua curta e bífida, anomalias dentarias, encurtamento mesomélico de membros, braquidactilia, clinodactilia, criptorquidia bilateral micropênis, hérnia inguinal, defeitos cardíacos e onfalocele. Foi submetido a um total de 23 cirurgias e foi examinado por nós após as correções cirúrgicas.

\section{Paciente 9}

Paciente do sexo feminino com 47 anos de idade, nascida nos Estados Unidos, filha de pais presumidamente consanguíneos de comunidade menonita. Ao exame clinico observou-se estatura limítrofe $\left(1,52\right.$, entre $3^{\circ}$ e $5^{\circ}$ percentis), macrocefalia (PC $59 \mathrm{~cm}$; >98ำ percentil), bossa frontal, hipertelorismo, olhos proeminentes, estrabismo, cílios longos, boca em forma de triangulo, lábio superior fino, língua bífida, hiperplasia gengival, fissura do palato mole, anomalias dentarias, encurtamento mesomélico de membros, limitação da supinação dos cotovelos, braquidactilia, clinodactilia, polegares alargados, displasia das unhas, pectus excavatum, hérnia inguinal, genitália hipoplásica com clitóris pequeno e agenesia dos pequenos lábios, fosseta sacral. Refere anomalias renais. Fez cirurgia plástica facial. Possui dois filhos sendo um menino normal e uma filha afetada (Paciente 10). 
Refere que seu pai é também afetado, mas como ele vive em comunidade menonita não tivemos acesso a ele ou mesmo fotos.

\section{Paciente 10}

Paciente do sexo feminino atualmente com 15 anos de idade, nascida nos Estados Unidos, filha de pais não consanguíneos, sendo a mãe também afetada (Paciente 9). Ao exame físico observou-se baixa estatura, bossa frontal, hipertelorismo, olhos proeminentes, cílios longos, nariz curto, narinas antevertidas, ponte nasal larga, hiperplasia gengival, boca triangular, boca em forma de cupido, lábio superior fino, língua bífida, anomalias dentarias, micrognatia, encurtamento mesomélico de membros, clinodactilia, primeiro dedo largo, braquidactilia, clitóris pequeno e agenesia dos pequenos lábios.

\section{Paciente 11}

Paciente do sexo masculino com 25 anos de idade, nascido nos Estados Unidos, filho de pais não consanguíneos. Ao exame clinico observou-se baixa estatura $\left(1,55,<3^{\circ}\right.$ percentil), normocefalia $\left(P C=54 \mathrm{~cm}, 25-50^{\circ}\right.$ percentis $)$, calvície frontal, olhos proeminentes, epicanto, esclerótica azul, cílios longos, fissuras palpebrais, nariz bulboso, ponte nasal larga, face media hipoplásica, boca triangular, cantos da boca voltados para baixo, fenda palatina, micrognatia, anormalidades dentarias, língua curta, clinodactilia, sindactilia, braquidactilia, displasia de unhas, hérnia umbilical, escoliose e anomalias renais. Nasceu com onfalocele. 


\section{IV.2- Diagnóstico Molecular}

A análise por sequenciamento Sanger dos exons 14 e 15 do gene DVL1, dos pacientes participantes dessa pesquisa revelou que quatro dos 11 pacientes eram portadores de mutação em heterozigose no exon 14 do gene DVL1.

O paciente 01 apresentou uma mutação no exon 14 identificada por uma mudança de fase no eletroferograma como mostra a Figura 13. A clonagem dos fragmentos ainda não foi concluída, portanto a posição exata da mutação não pôde ser confirmada. A análise in silico sugere uma deleção de $13 \mathrm{pb}$.

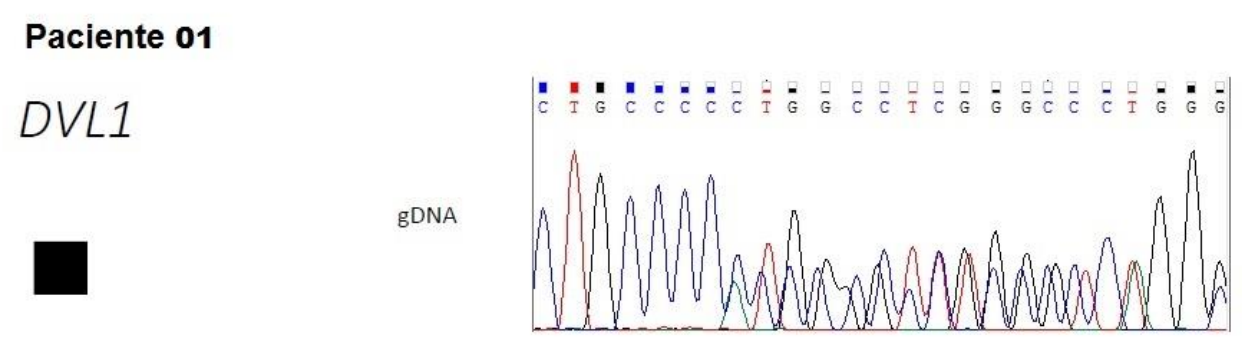

Figura 03: Segmento do eletroferograma do sequenciamento Sanger do exon 14 do gene DVL1 para o Paciente 01.

A segunda mutação encontrada foi na amostra do paciente 02 , onde identificamos pelo sequenciamento uma variante patogênica no gene DVL1. Esta deleção de 13 pares de bases está na posição c.1505_1517del; P.His502Profs * 143, confirmada pela clonagem do fragmento (Figura 14). Esta variante afeta o exon 14 de DVL1 sendo uma mutação de mudança no quadro de leitura, isto é, é predita a alteração da estrutura de leitura de tradução da extremidade $C$ terminal da proteína DVL1 que provavelmente tem consequências patogênicas. 


\section{Paciente 02}

\section{DVL1}

gDNA
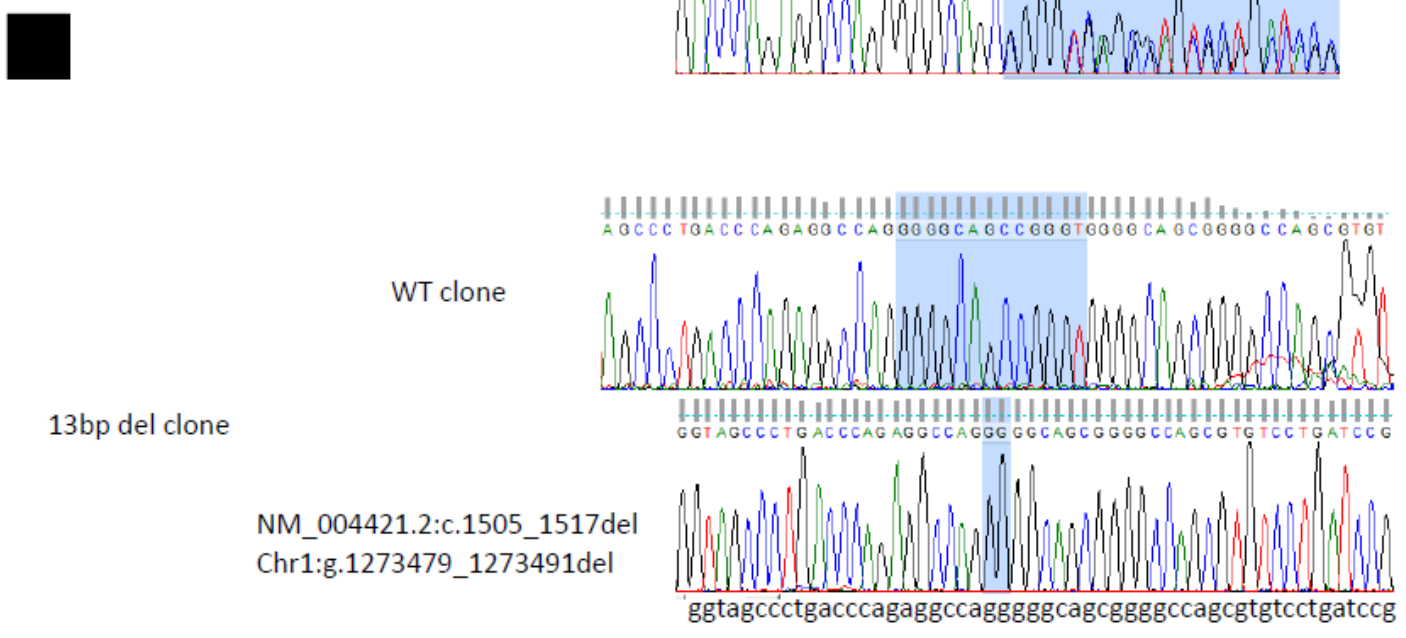

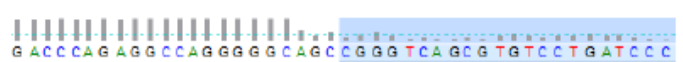

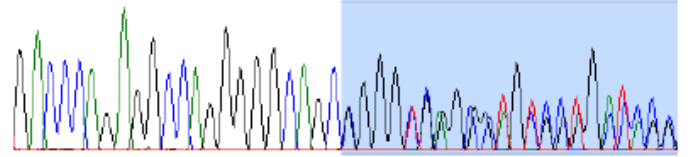

Figura 04: Segmento dos eletroferogramas do sequenciamento Sanger do exon 14 do gene DVL1 para o Paciente 02 antes e após a clonagem.

O terceiro resultado positivo se deu no paciente 06, por uma inserção de 5 pares de bases na posição c.1612_1616dup; P.Ser539Argfs * 112 (Figura 15). Essa mutação altera o quadro de leitura, sendo provavelmente patogênica.

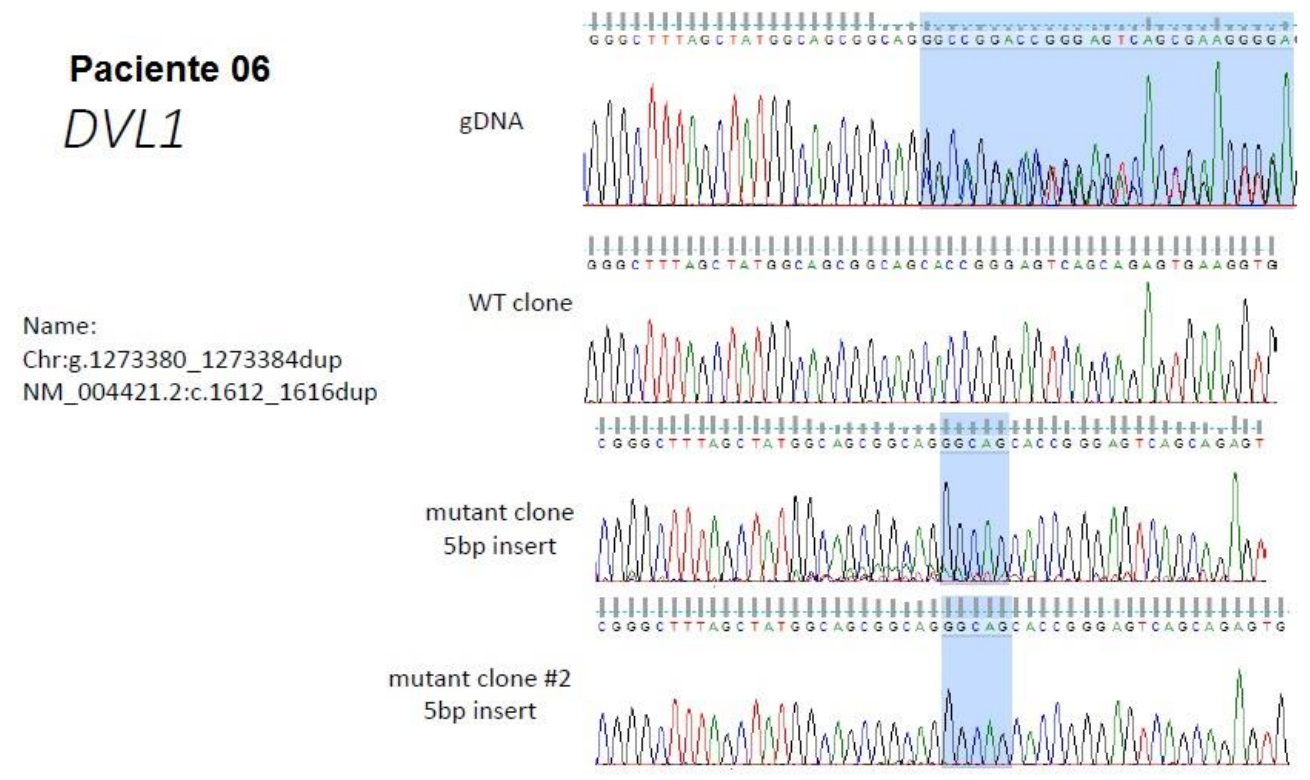

Figura 05: Segmento dos eletroferogramas do sequenciamento Sanger do exon 14 do gene DVL1 para o Paciente 06 antes e após a clonagem. 
O paciente 07 também teve sua amostra positiva ao sequenciamento, onde identificamos uma deleção de 13 pares de bases na posição c.1496_1508; p.Pro499Argfs * 146. Esta variante altera o exon 14 de DVL1, como mostra o resultado do sequenciamento (Figura 16).

\section{Paciente 07}

DVL1

Name:

Chr:g.1273488_1273500

NM_004421.2:c.1496_1508del

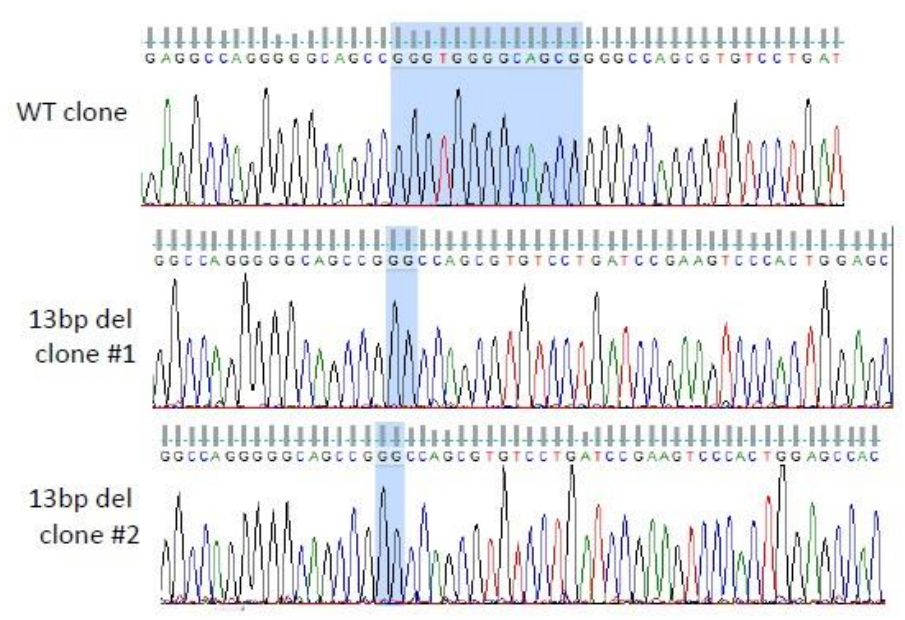

Figura 06: Segmento dos eletroferogramas do sequenciamento Sanger do exon 14 do gene DVL1 para o Paciente 07 antes e após a clonagem.

Os demais pacientes não apresentaram mutação nos exons 14 e 15 do gene DVL1. No paciente 11 foi detectada mutação no gene DVL3 como parte de outro projeto de pesquisa.

A figura 17 representa a posição das mutações descritas na literatura e do presente trabalho no gene DVL1. Todas as variantes estão localizadas dentro de uma faixa de aproximadamente 110 nucleotídeos no penúltimo exon, e todos são deleções que resultam em uma mudança no quadro de leitura. 


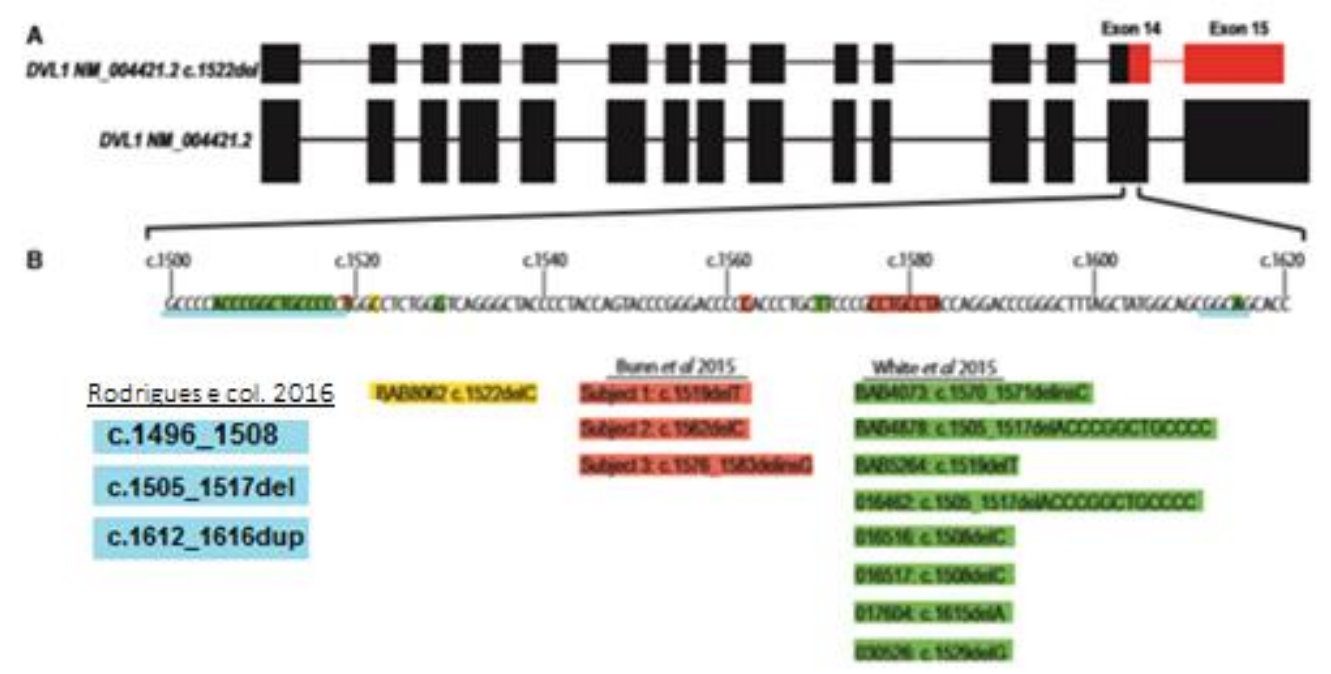

Figura 07: Locais de todas as variantes descritas na literatura e em nosso trabalho atualmente no gene $D V L 3$ da SR. A cor preta representa regiões idênticas ao tipo selvagem $D V L 1$, e vermelho indica a região de codificação mutante, a cor laranja indica nucleotídeos eliminados em indivíduos relatados por Bunn e cols., o verde representa os de White e cols,2015, amarelo White cols., 2016 e a cor azul representa os afetados dessa pesquisa.

Até o momento haviam sido descritas na literatura 12 diferentes mutações como mostra a Figura 17 e a Tabela 03. Comparando os nossos resultados com os anteriormente descritos, observamos que nenhuma das três mutações encontradas em nosso trabalho havia sido reportada na literatura.

A família de proteínas Dishevelled (DSH), originalmente descoberta em Drosophila melanogaster, é essencial para padronização tecidual. Drosophila DSH evoluiu três ortólogos em mamíferos: os genes homólogos $D v / 1, D v / 2$, e $D v / 3$, que compartilham de $59 \%-67 \%$ de homologia de aminoácidos, e tem uma localização uniforme de variantes associadas a doenças na SR. No modelo animal, $D v / 1$ e $D v / 3$ são localizados no interior do tubo neural em desenvolvimento, e todas as três proteínas Dvl têm padrões de localização semelhantes(24).

Nossos dados apoiam fortemente estudos anteriores relatando que mudanças específicas do quadro de leitura no penúltimo exon do DVL1 causam DRS. A literatura atual indica que estas variantes estão aglomeradas no penúltimo exon e produzem uma cauda de peptídeo C-terminal mutante que é altamente básica e rica em prolina, e maior do que 100 aminoácidos de comprimento. White e cols., relataram que a função exata da cauda C-terminal é desconhecida, mas os últimos 35 aminoácidos têm sido mostrados conservados entre todas as proteínas preditas. 
Tabela 03: Mutações encontradas no presente trabalho e reportadas na literatura em pacientes com a forma autossômica dominante da síndrome de Robinow $(15,16,17)$.

\begin{tabular}{lcc}
\hline Alterações de Base & Sexo & País de nascimento \\
\hline c.1570_1571delC & $\mathrm{F}$ & EUA \\
c.1505_1517delACCCGGCTGCCC & $\mathrm{F}$ & EUA \\
c.1519delT & $\mathrm{M}$ & EUA \\
c.1505_1517delACCCGGCTGCCC & $\mathrm{F}$ & Dinamarca \\
c.1508delC & $\mathrm{M}$ & Portugal \\
c.1508delC & $\mathrm{M}$ & Portugal \\
c.1615delA & $\mathrm{M}$ & Turquia \\
c.1529delG & $\mathrm{F}$ & EUA \\
c.1519delT & $\mathrm{F}$ & - \\
c.1562delC & $\mathrm{M}$ & Nova Zelândia \\
c.1576_1583delG & $\mathrm{F}$ & - \\
$?$ & $\mathrm{M}$ & EUA \\
c.1505_1517del & $\mathrm{M}$ & Argentina \\
c.1612_1616dup & $\mathrm{M}$ & EUA \\
c.1496_1508del & $\mathrm{F}$ & Inglaterra \\
\hline
\end{tabular}


A sinalização Wnt é uma via altamente conservada envolvida na proliferação celular, migração e estabelecimento de polaridade celular planar, em organismos eucarióticos. Nos seres humanos, os alelos hipomórficos e mutações de perda de função dos genes WNT5A e ROR2, respectivamente, ambas as quais codificam proteínas envolvidas na cascata de sinalização não canônicas, b-catenina independente, levam a DRS e RRS, respectivamente(25).

É interessante notar que os genes causativos para a síndrome de Robinow já descritos incluindo WNT5A, ROR2, DVL1 e DVL3 fazem parte da sinalização Wnt não-canônica. WNT5A atua como ligante do receptor de membrana ROR2 que transduz o sinal via Dishevelled. ROR2 parece participar apenas da via PCP e desta forma a alteração dessa via de sinalização deve ser a principal causa das alterações fenotípicas da síndrome. Mais trabalhos são necessários para elucidar o mecanismo pelo qual as mutações em DVL1 e DVL3 resultam em DRS e suas interações dentro da via de sinalização Wnt.

São necessários mais estudos para investigar se as mutações no exon 14 do DVL1 DRS-associado produz uma proteína com atividade residual que compete com a proteína de tipo selvagem e perturba a sua função (anamórfica) ou se o novo domínio C-terminal executa uma nova, imprevisível papel biológico (neomórfica). Em qualquer caso, uma proteína alterada dominante negativo ou o ganho ou perda de função está previsto para contribuir para a doença dominante(16).

O trabalho de Mazzeu e cols. em 2007 reportou a frequência de 75 sinais e sintomas em pacientes com as formas dominante e recessiva em pacientes novos e já descritos na literatura. Esse trabalho estimou as frequências de cada sinal levando em conta a possibilidade dele estar ou não ausente quando não era reportado. Com base na descrição clínica de nossos pacientes, construímos a Tabela 04 que mostra as frequências encontradas no trabalho de Mazzeu e cols., (2007) e a presença desses sinais em nossa amostra. Importante ressaltar que foram adicionadas apenas as características com frequência $>25 \%$ de acordo com o trabalho de realizado por Mazzeu e cols. 2007. 
Tabela 4:Características clinicas dos pacientes investigados no presente estudo e frequência desses sinais na forma autossômica dominante da síndrome (6).

\begin{tabular}{|c|c|c|c|c|c|c|c|c|c|c|c|c|c|c|}
\hline Característica & $\%$ * & $\mathbf{n}$ & $\%$ & PCT 1 & PCT 2 & PCT3 & PCT 4 & PCT 5 & PCT 6 & PCT 7 & PCT 8 & PCT 9 & PCT 10 & PCT 11 \\
\hline Macrocefalia & 64 & $07 / 11$ & 63 & + & + & \# & + & - & + & + & + & + & - & - \\
\hline Bossa frontal & & $07 / 11$ & 63 & + & + & + & - & + & + & - & - & + & + & - \\
\hline Olhos proeminentes & 36 & $07 / 11$ & 63 & + & - & - & + & - & + & + & - & + & + & + \\
\hline Hipertelorismo & 100 & $11 / 11$ & 100 & + & + & + & + & + & + & + & + & + & + & + \\
\hline Estrabismo & 12 & $03 / 11$ & 27 & - & - & - & + & + & - & - & - & + & - & - \\
\hline Cílios Longos & 54 & $05 / 11$ & 45 & - & - & - & + & + & - & - & - & + & + & + \\
\hline Ptose & 14 & $01 / 11$ & 09 & + & - & - & - & - & - & - & - & - & - & - \\
\hline Epicanto & 39 & $05 / 11$ & 45 & + & \# & + & + & - & - & - & + & - & - & + \\
\hline Ponte Nasal Larga & 100 & $11 / 11$ & 100 & + & + & + & + & + & + & + & + & + & + & + \\
\hline Nariz curto & 81 & $08 / 11$ & 71 & + & + & + & + & + & - & + & - & + & + & - \\
\hline Narinas Antevertidas & 100 & $09 / 11$ & 80 & + & - & + & + & + & + & + & + & + & + & - \\
\hline Nariz bulboso & & $06 / 11$ & 54 & - & - & + & + & + & + & + & - & - & - & + \\
\hline Nevo facial & 19 & $04 / 11$ & 36 & - & - & - & - & + & - & - & + & + & + & - \\
\hline $\begin{array}{l}\text { Hipoplasia Terço Médio } \\
\text { da Face }\end{array}$ & 80 & $11 / 11$ & 100 & + & + & + & + & + & + & + & + & + & + & + \\
\hline Filtro Curto & 16 & $02 / 11$ & 18 & - & * & * & + & + & - & - & - & - & - & - \\
\hline Filtro longo & 64 & $05 / 11$ & 45 & + & * & * & - & - & + & + & + & - & - & + \\
\hline
\end{tabular}


Tabela 04: Continua.

\begin{tabular}{|c|c|c|c|c|c|c|c|c|c|c|c|c|c|c|}
\hline Característica & $\%$ * & $\mathbf{n}$ & $\%$ & PCT 1 & PCT 2 & PCT3 & PCT 4 & PCT 5 & PCT 6 & PCT 7 & PCT 8 & PCT 9 & PCT 10 & PCT 11 \\
\hline $\begin{array}{l}\text { Cantos da Boca voltados } \\
\text { para Baixo }\end{array}$ & 62 & $04 / 11$ & 36 & + & - & - & - & + & + & - & - & - & - & + \\
\hline Boca triangular & 65 & $07 / 11$ & 63 & + & - & - & - & + & + & + & - & + & + & + \\
\hline Hiperplasia gengival & 35 & $10 / 11$ & 90 & + & + & \# & + & + & + & + & + & + & + & + \\
\hline Anomalias dentárias & 49 & $10 / 11$ & 90 & + & + & \# & + & + & + & + & + & + & + & + \\
\hline Lábio Superior Fino & 49 & $06 / 11$ & 54 & + & - & - & - & + & + & - & + & + & + & - \\
\hline Fenda labial/palatina & 34 & $04 / 11$ & 36 & + & + & + & - & - & + & - & - & - & - & - \\
\hline Língua Bífida & 38 & $07 / 11$ & 63 & + & + & - & + & - & + & + & - & + & + & - \\
\hline Lingua curta & & $10 / 11$ & 90 & + & + & - & + & + & + & + & + & + & + & + \\
\hline Palato alto & 51 & $04 / 11$ & 36 & + & + & \# & + & - & + & - & - & - & - & - \\
\hline Micrognatia & 56 & $07 / 11$ & 63 & + & + & - & + & + & - & + & - & - & + & + \\
\hline Retrognatia & 44 & $04 / 11$ & 36 & - & - & + & + & + & - & - & - & - & - & + \\
\hline Pescoço curto & 29 & $02 / 11$ & 18 & + & - & - & - & - & + & - & - & - & - & - \\
\hline Baixa Estatura & 81 & $04 / 11$ & 36 & - & - & - & + & - & - & - & - & + & + & + \\
\hline Hemivértebra & 22 & $02 / 11$ & 18 & - & - & + & - & + & - & - & - & - & - & - \\
\hline Criptorquidia & 71 & $06 / 07$ & & + & + & + & NA & + & + & NA & + & NA & NA & \# \\
\hline Clitóris Hipoplásico & 45 & $02 / 04$ & 50 & NA & NA & NA & \# & NA & NA & \# & NA & + & + & NA \\
\hline
\end{tabular}




\begin{tabular}{|c|c|c|c|c|c|c|c|c|c|c|c|c|c|c|}
\hline Característica & $\%$ * & $\mathbf{n}$ & $\%$ & PCT 1 & PCT 2 & PCT3 & PCT 4 & PCT 5 & PCT 6 & PCT 7 & PCT 8 & PCT 9 & PCT 10 & PCT 11 \\
\hline $\begin{array}{l}\text { Hipoplasia Grandes } \\
\text { Lábios }\end{array}$ & 34 & $02 / 04$ & 50 & NA & NA & NA & \# & NA & NA & \# & NA & + & + & NA \\
\hline $\begin{array}{l}\text { Pequenos Lábios } \\
\text { Hipoplásicos }\end{array}$ & 50 & $02 / 04$ & 50 & NA & NA & NA & \# & NA & NA & $\#$ & NA & + & + & NA \\
\hline Fosseta sacral & 14 & $03 / 11$ & 27 & - & - & - & - & - & + & - & \# & + & + & - \\
\hline Infecções respiratórias & 25 & $03 / 11$ & 27 & + & + & - & - & - & + & - & - & - & - & - \\
\hline Defeitos cardíacos & 28 & $05 / 11$ & 45 & - & - & - & - & + & + & + & + & - & - & + \\
\hline Anomalias renais & 26 & $03 / 11$ & 27 & - & - & - & - & - & - & - & - & + & + & + \\
\hline Hérnia umbilical & 32 & $05 / 11$ & 45 & + & - & - & - & - & + & + & + & - & - & + \\
\hline Hérnia inguinal & 16 & $05 / 11$ & 45 & + & - & + & - & + & + & - & + & - & - & - \\
\hline Outros & & & & $\begin{array}{l}\text { Pulmões } \\
\text { colapsad } \\
\text { os }\end{array}$ & & $\begin{array}{l}\begin{array}{l}\text { Bexiga } \\
\text { pequena }\end{array} \\
\text { Adução } \\
\text { do } \\
\text { polegar, } \\
\text { Vertebras } \\
\text { em } \\
\text { borboleta }\end{array}$ & & & $\begin{array}{l}\text { Espinha } \\
\text { bífida, } \\
\text { tórax } \\
\text { estreito, } \\
\text { surdez. }\end{array}$ & & & Anosmia & & $\begin{array}{l}\text { Pectus } \\
\text { Carinatumo } \\
\text { nfalocele }\end{array}$ \\
\hline País de nascimento & & & & EUA & ARG & EUA & EUA & CAN & EUA & UK & EUA & EUA & EUA & EUA \\
\hline Sexo & & & & $M$ & M & $M$ & $\mathrm{~F}$ & M & $M$ & $\mathrm{~F}$ & $M$ & $\mathrm{~F}$ & $\mathrm{~F}$ & M \\
\hline
\end{tabular}

- $\quad$ \% segundo Mazzeu e cols., + presente / - ausente / NA não aplica / \# Não avaliado. 
Observamos que os nossos pacientes apresentam frequências semelhante as do trabalho de Mazzeu e cols., (2007) para a maior parte dos sinais clínicos. O fenótipo dos indivíduos do presente estudo é concordante com as descrições clínicas anteriores da DRS (Tabela 4). As características típicas faciais como hipertelorismo e hipoplasia do terço médio da face foram observados em 100\% dos indivíduos afetados. Todos apresentavam anomalias congênitas adicionais, incluindo micropênis (6/7 indivíduos do sexo masculino), hipoplasia genital (2/4mulheres), hérnias umbilicais (5/11 indivíduos), malformações cardíacas (4/11 indivíduos), anomalias renais (3/11 indivíduos), e ponte nasal larga (10/11 indivíduos) (Tabela 4).

O diagnóstico diferencial de RRS e DRS baseia-se na presença de fusões de costelas, que se encontra exclusivamente em pacientes com RRS, e, em casos familiais, também pelo padrão de herança. Nossa análise mostra que o diagnóstico diferencial da RRS e DRS é facilitado por sinais adicionais que têm frequências distintas nas duas variantes. Por exemplo, hemivértebra e escoliose ocorrem com frequências de $97,5 \%$ e $77,4 \%$, respectivamente, em pacientes com RRS; suas frequências correspondentes em pacientes com DRS são 22,7 e 17,6\%, respectivamente. Estes defeitos em associação com fusões costela caracterizam os defeitos de segmentação costovertebral típicos de pacientes com RRS (6).

A baixa estatura foi uma característica em que houve uma frequência destoante entre os dois trabalhos, pois a literatura apresenta $81 \%$ e no nosso trabalho apenas quatro dos 11 pacientes tinham baixa estatura. Quando consideramos apenas os pacientes com mutação em $D V L 1$ todos tinham estatura normal na idade adulta(16). No entanto, os pacientes tem registro de baixa estatura na infância e posteriormente alcançam estatura normal, porém abaixo do canal familiar. O presente trabalho inclui principalmente indivíduos adultos e por isso a frequência de baixa estatura foi menor. Já os indivíduos com mutação em DVL3 têm baixa estatura mesmo na idade adulta (17). A macrocefalia também estava presente em todos os pacientes com mutação em $D V L 1$ e em apenas 2 dos 6 pacientes sem mutação identificada.

A hiperplasia gengival estava presente em $90 \%$ dos pacientes do nosso trabalho enquanto que no trabalho anterior a frequência era de 38,5\% (6). Esse sinal é muito frequente, no entanto, pouco relatado na literatura mostrando a importância 
da inclusão de pacientes bem caracterizados clinicamente e da avaliação multidisciplinar desses pacientes.

Bunn e cols (2015) e White e cols (2015) relataram osteoesclerose em pacientes com SR e mutações em DVL1 Os pacientes incluídos no presente trabalho não puderam ser avaliados quanto à densidade óssea.

A análise de pacientes com a síndrome de Robinow agrupados de acordo com o gene mutado poderá fornecer frequências mais precisas dos sinais clínicos e a diferenciação de formas clinicas.

A identificação do gene mutado nos demais pacientes poderá contribuir na elucidação não apenas nas diferentes formas clínicas mas no entendimento da via não canônica de WNTs.

Os dados do presente trabalho certamente contribuirão para a melhor caracterização do quadro clínico associado a mutações no gene DVL1. 


\section{Conclusões}

Nossa pesquisa contou com 11 pacientes com a forma autossômica dominante da síndrome de Robinow, dos quais quatro apresentaram mutação em DVL1.

As 03 mutações já clonadas e sequenciadas que levavam a mudanças no quadro de leitura e não foram descritas previamente na literatura. Portanto, nosso trabalho contribui para composição do quadro de mutações patogênicas associadas à síndrome.

A caracterização clinica detalhadas mostrou que a frequência de alguns sinais era discordante da literatura mostrando a importância de uma caracterização precisa de um grupo maior de pacientes principalmente para se estabelecer um melhor entendimento da relação genótipo/fenótipo.

Os pacientes estudados com mutação em DVL1 não apresentam baixa estatura na idade adulta, como já sugerido na literatura.

Todos os pacientes com mutação em DVL1 apresentaram macrocefalia enquanto a frequência foi menos nos indivíduos sem mutação (2/6).

A identificação de novos genes e a descrição clínica de pacientes com mutações e cada um dos genes causativos irá contribuir para a melhor caracterização da síndrome e melhor entendimento da via não canônica de WNTs. 


\section{Referências Bibliográficas}

1. Robinow M, Silverman FN, Smith HD. A newly recognized dwarfing syndrome. Am J Dis Child 1969;117:645-51.

2. Wadia, R. S., D. B. Shirole, and M. S. Dikshit. "Recessively inherited costovertebral segmentation defect with mesomelia and peculiar facies (Covesdem syndrome): A new genetic entity?." Journal of medical genetics 15.2 (1978): 123-127.

3. Shprintzen Rj, Goldberg Rb, Saenger P, Sidoti Ej.Male-to-male transmission of Robinow's syndrome. Its occurrence in association with cleft lip and cleft palate. Am J Dis Child. 1982 Jul;136(7):594-7.4.

4. Ak ${ }^{\circ}$ it $S$,Aydinlioglu H,Dizdarer G,Caglayan S,Bekta $\%$ ar D, Cin A.Is the frequency of Robinow syndrome relatively high in Turkey? Four more case reports.Clin Genet. 1997 52(4):226 -30.

5. Mazzeu, J.F., Pardono, E., Vianna-Morgante, A.M., Richieri-Costa, A., Ae Kim, C., Brunoni, D., Martelli, L., de Andrade, C.E., Colin, G., and Otto, P.A. (2007). Clinical characterization of autosomal dominant and recessive variants of Robinow syndrome. Am. J. Med. Genet. A. 143, 320-325.

6. Mazzeu, Juliana Forte. Estudo genético-clínico da Síndrome de Robinow. Diss. Universidade de São Paulo (USP). Instituto de Biociências, 2005.

7. Robinow M. The Robinow (fetal face) syndrome: a continuing puzzle. Clin Dysmorphol 1993;2:189-98

8. Afzal Ar, Rajab A, Fenske C, Crosby A, Lahiri N, Ternes-Pereira E,Murday Va, Houlston R, Patton Ma, Jeffery S. Linkage of recessive Robinow syndrome to a $4 \mathrm{cM}$ interval on chromosome 9q22. Hum Genet 2000;106:351-4.

9. Van Bokhoven H, Celli J, Kayserili H, Balci S, Brussel W,Skovby F, Kerr B, Percin $\mathrm{E}$, Akarsu N, Brunner Hg. Mutation of the gene encoding the ROR2 tyrosine kinase causes autosomal recessive Robinow syndrome. Nat Genet 2000;25:423-6. Erratum in Nat Genet 2000;26:383

10. Schwabe G, Trepczik B, Kathrin S, Brieske N, Tucker A.. Sharpe P, Minami Y, And Mundlos S. Ror2 Knockout Mouse as a Model for the Developmental Pathology 
of Autosomal Recessive Robinow Syndrome. Developmental dynamics 2004; 229:400 - 410 .

11. He F, Xiong W, Yu X, Espinoza-Lewis R,Liu C, Gu S, Nishita M, Suzuki K,Yamada G, Minami Y, Chen Y. Wnt5a regulates directional cell migrationand cell proliferation via Ror2-mediated noncanonical pathway inmammalian palate development. Development 2008 135:3871-3879

12. Oishi I, Suzuki H, Onishi N Et Al. The receptor tyrosine kinase Ror2 is involved in non-canonical Wnt5a/JNK signalling pathway. Genes Cells 2003: 8 (7): 645-654.

13. Person, A.D., Beiraghi, S., Sieben, C.M., Hermanson, S., Neu-mann, A.N., Robu, M.E., Schleiffarth, J.R., Billington, C.J., Jr., van Bokhoven, H., Hoogeboom, J.M., et al. (2010). WNT5A mutations in patients with autosomal dominant Robinow syndrome. Dev. Dyn. 239, 327-337.

14. Roifman, M., Marcelis, C.L.M., Paton, T., Marshall, C., Silver, R., Lohr, J.L., Yntema, H.G., Venselaar, H., Kayserili, H., van Bon, B., et al.; FORGE Canada Consortium (2015). De novo WNT5A-associated autosomal dominant Robinow syndrome suggests specificity of genotype and phenotype. Clin. Genet. 87, 34-41.

15. Bunn, K.J., Daniel, P., Ro"sken, H.S., O'Neill, A.C., Cameron-Christie, S.R., Morgan, T., Brunner, H.G., Lai, A., Kunst, H.P.M., Markie, D.M., and Robertson, S.P. (2015). Mutations in DVL1 cause an osteosclerotic form of Robinow syndrome. Am. J. Hum. Genet. 96, 623-630.

16. White, J., Mazzeu, J.F., Hoischen, A., Jhangiani, S.N., Gambin, T., Alcino, M.C., Penney, S., Saraiva, J.M., Hove, H., Skovby, F., et al.; Baylor-Hopkins Center for Mendelian Genomics (2015). DVL1 frameshift mutations clustering in the penultimate exon cause autosomal-dominant Robinow syndrome. Am. J. Hum. Genet. 96, 612622.

17. White, Janson J., et al. "DVL3 alleles resulting in a- 1 frameshift of the last exon mediate autosomal-dominant Robinow syndrome." The American Journal of Human Genetics 98.3 (2016): 553-561

18. Polakis, P. Wnt signaling in cancer. Cold Spring Harb. Perspect. Biol.2012 1;4(5). 
19. Yasuhiro M, Isao Oishi, Mitsuharu Endo, and Michiru Nishita. Ror-Family Receptor Tyrosine Kinases in Noncanonical Wnt Signaling: Their Implications in Developmental Morphogenesis and Human Diseases Developmental dynamics, 2010. 239:1-15.

20. Chen, W., D. ten Berge, J. Brown, S. Ahn, L.A. Hu, W.E. Miller, M.G. Caron, L.S. Barak, R. Nusse, and R.J. Lefkowitz. 2003. Dishevelled 2 recruits beta-arrestin 2 to mediate Wnt5A-stimulated endocytosis of Frizzled 4. Science. 301:1391-1394.

21. Tauriello, D.V., I. Jordens, K. Kirchner, J.W. Slootstra, T. Kruitwagen, B.A. Bouwman, M. Noutsou, S.G. Rudiger, K. Schwamborn, A. Schambony, and M.M. Maurice. 2012. Wnt/beta-catenin signaling requires interaction of the Dishevelled DEP domain and $C$ terminus with a discontinuous motif in Frizzled. Proceedings of the National Academy of Sciences of the United States of America. 109:E812-820.

22. Fiedler, M., C. Mendoza-Topaz, T.J. Rutherford, J. Mieszczanek, and M. Bienz. 2011. Dishevelled interacts with the DIX domain polymerization interface of Axin to interfere with its function in down-regulating beta-catenin. Proceedings of the National Academy of Sciences of the United States of America. 108:1937-1942.

23. Schwarz-Romond, T., M. Fiedler, N. Shibata, P.J. Butler, A. Kikuchi, Y. Higuchi, and M. Bienz. 2007. The DIX domain of Dishevelled confers Wnt signaling by dynamic polymerization. Nature structural \& molecular biology. 14:484-492.

24. Gray, Ryan S. et al. "Diversification of the Expression Patterns and Developmental Functions of the Dishevelled Gene Family during Chordate Evolution." Developmental dynamics : an official publication of the American Association of Anatomists 238.8 (2009): 2044-2057. PMC. Web. 28 Nov. 2016.

25. Yamaguchi, T.P., Bradley, A., McMahon, A.P., and Jones, S. (1999). A Wnt5a pathway underlies outgrowth of multiple structures in the vertebrate embryo. Development 126, 1211-1223. 
Anexo 01

$\operatorname{DATA} \ldots / \ldots / \ldots$.

REGISTRO LGH №.

RESPONSÁVEL PELO CASO

PACIENTE

DATA DE NASC. ../ $\ldots / \ldots \ldots$

SEXO

. GRUPO RACIAL

LOC. DE NASC.

ENDEREÇO

CIDADE

ESTADO

CEP

TELEFONE $(\ldots \ldots)$

OBS :

MÉDICO

TELEFONE (...)

$\mathrm{MÃE}$

PROFISS ̃̃O

IDADE ....ANOS

PAI

PROFISSÃO

IDADE ....ANOS

ESCOLARIDADE

MOTIVO DA CONSULTA 
1) ANAMNESE GERAL

1.1) Antecedentes pré-natais (gestação)

pré-natal $(s / n) \ldots$ duração ........ medicamentos..........

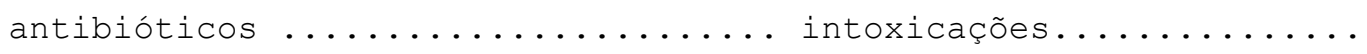

exposição a radiações.............. outras intercorrências ...

1.2) Antecedentes perinatais

parto ...... índ. de $\operatorname{Apgar}(s / n) \ldots \operatorname{choro}(s / n) \ldots \operatorname{cianose}(s / n) \ldots$

peso .......kg comprimento .......cm per.cefálico .......cm

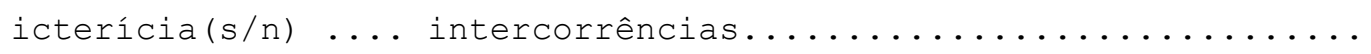


1.3) Evolução neuro-psico-motora

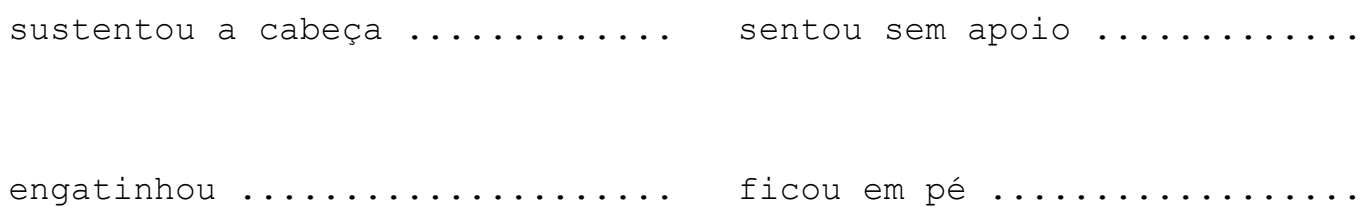

andou sem apoio.......... falou primeiras palavras.......

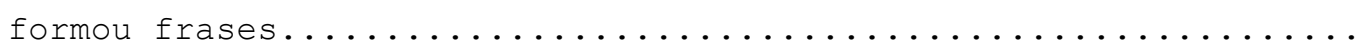

controle vesical (diurno) $\ldots \ldots \ldots \ldots$ (noturno) $\ldots \ldots \ldots$

controle anal (diurno) $\ldots \ldots \ldots \ldots \ldots \ldots$ (noturno) $\ldots \ldots \ldots$

1.4) Escolaridade

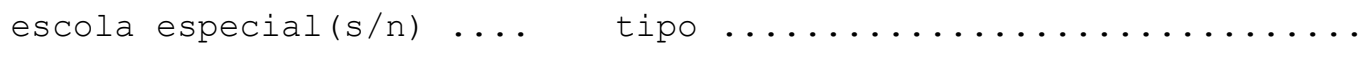

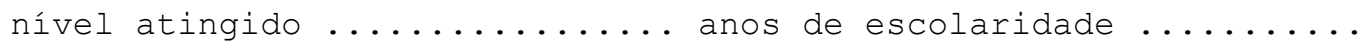

1.5) História patológica pregressa

doenças

internações

cirurgias 
3) EXAME FÍSICO

Data do exame ................

3.1) Geral

peso .....kg altura .....cm perímetro cefálico ......cm

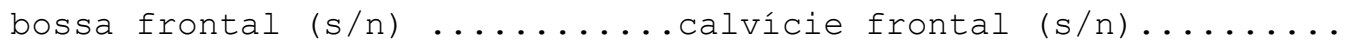

hipoplasia de face média $(s / n) \ldots \ldots \ldots \ldots$

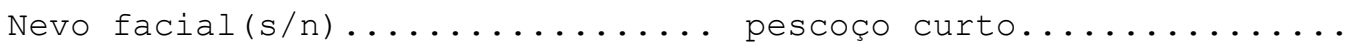

3.2) Região orbitária

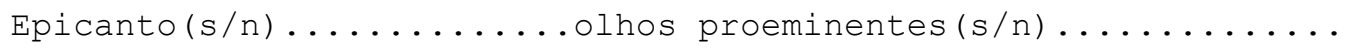

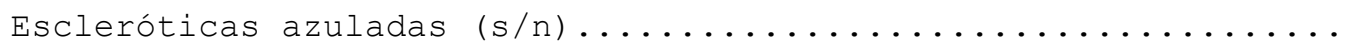

Fissuras palpebrais .........estrabismo (s/n) ..........

Cílios longos $(s / n) \ldots \ldots \ldots \ldots$. . . . . .

distância intercantal interna.............mm

distância intercantal externa ..............mm

distância bipupilar ...............mm 
3.3) Região nasal

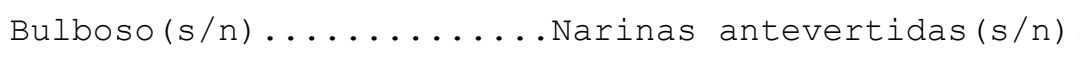

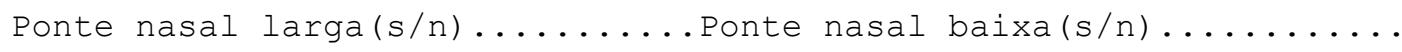

Filtro (longo/curto) $\ldots \ldots \ldots \ldots$

3.4) Região buco-mandibular

Boca triangular $(\mathrm{s} / \mathrm{n})$

Cantos da boca voltados para baixo (s/n) .....

Lábio superior fino $(s / n) \ldots \ldots \ldots \ldots \ldots \ldots \ldots \ldots \ldots \ldots \ldots \ldots$

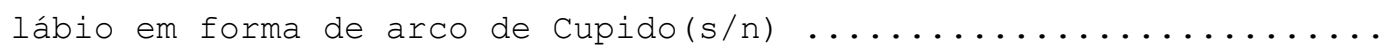

lábio leporino $(s / n) \ldots \ldots$ palato fendido $(s / n) \ldots \ldots$

palato alto $(s / n) \ldots \ldots$ palato ogival $(s / n) \ldots \ldots$

língua bilobada $(s / n) \ldots \ldots$ hiperplasia de gengiva $(s / n) \ldots \ldots$

micrognatia $(s / n) \ldots \ldots$ retrognatia $(s / n) \ldots \ldots \ldots$

anomalias dentárias : 
3.5) Genitália

Hipoplásica $(\mathrm{s} / \mathrm{n})$ ambígua $(\mathrm{s} / \mathrm{n})$

Fosseta sacral (s/n)

3.5.1) Masculina

Pênis pequeno $(s / n) \ldots \ldots \ldots$ criptorquidismo $(s / n) \ldots \ldots \ldots$

escroto em cachecol $(\mathrm{s} / \mathrm{n}) \ldots \ldots \ldots$

3.5.2) Feminina

Hipolasia de:

Clitóris $(s / n) \ldots \ldots \ldots \ldots \ldots$

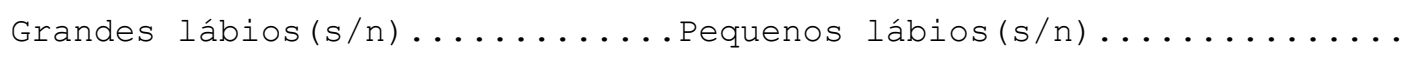


3.6) Membros superiores

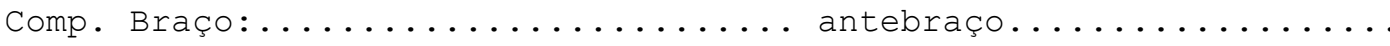

Displasia mesomélica $(s / n) \ldots \ldots \ldots \ldots \ldots$

\subsection{1) Mãos}

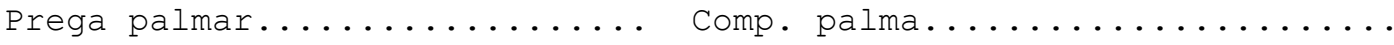
Comp. dedo médio ............ Braquidactilia (s/n)

Polegar alargado $(s / n) \ldots \ldots$ Displasia de unhas $(s / n) \ldots \ldots$ Clinodactilia $(s / n) \ldots \ldots$ Sindactilia $(s / n) \ldots \ldots . \ldots$

3.7) Membros inferiores

Comp. ................Joelho alargado (s/n)

3.7.1) Pés

Comprimento............ Displasia de unhas (s/n)

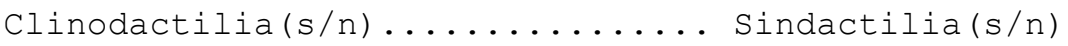


3.8) Outros

Distância intermamilar............

Pectus excavatum $(s / n) \ldots \ldots \ldots \ldots$

Hérnia umbilical $(\mathrm{s} / \mathrm{n}) \ldots \ldots \ldots \ldots \ldots$

Hérnia inguinal $(s / n) \ldots \ldots \ldots \ldots$

Hepatosplenomegalia $(\mathrm{s} / \mathrm{n}) \ldots \ldots \ldots \ldots$

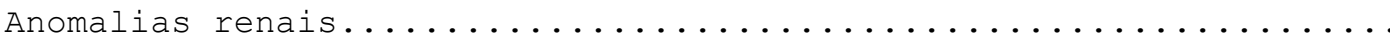

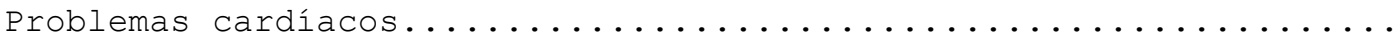

3.9) Exames especializados

3.9.1) exame radiológico

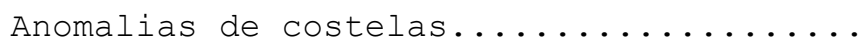

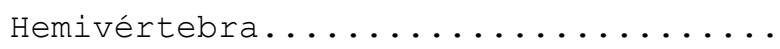

3.9.2) audiometria

3.9.3) outros 
4.0) Informações dos familiares (caso haja outro afetado na família
preencher outra ficha)

4.1) Mãe

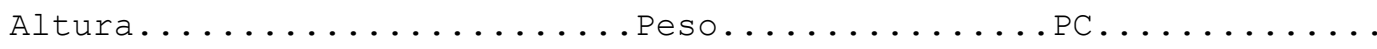

distância intercantal interna..............mm

distância intercantal externa .............mm

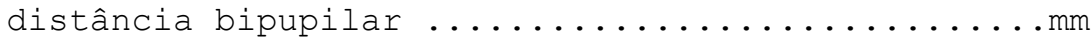

outros sinais:

4.2) $\mathrm{Pai}$

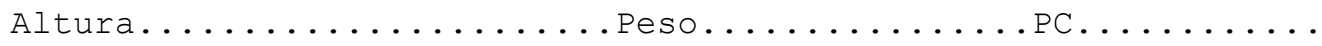

distância intercantal interna.............mm

distância intercantal externa $\ldots \ldots \ldots \ldots \ldots \ldots \ldots$

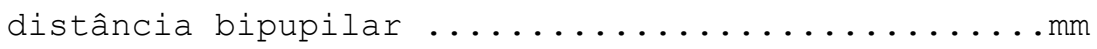

outros sinais: 
4.3) outros familiares

5) FOTOGRAFIAS DO PROPÓSITO E DE OUTROS FAMILIARES NORMAIS E AFETADOS

Propósito

Corpo inteiro: Frente e perfil

Rosto: Frente e perfil

Genitália

Mãos

Outros sinais importantes:

Familiares normais: Rosto

6) CÓPIA DO EXAME RADIOLÓGICO QUANDO ALTERADO (SE POSSÍVEL)

7) GENEALOGIA (verso)

Material a ser coletado :

$6 \mathrm{ml}$ de sangue em tubo heparinizado

$2 \times 4 \mathrm{ml}$ de sangue em tubo com EDTA 
Anexo 02

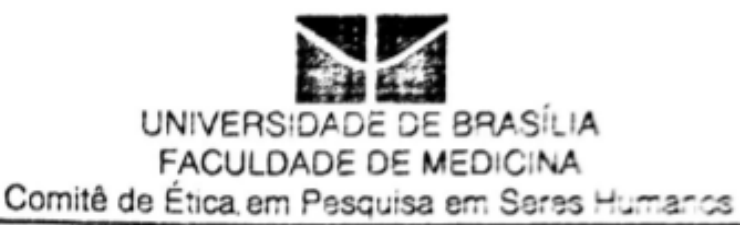

ANÁLISE DE PROJETO DE PESQLISA

Registro de Projeto: CEP-FM 082/2009.

Título: "Pesquisa de genes candidatos para a síndrome de Robinow".

Pesquisador Responsável: Juliana Forte Mazzeu de Araújo.

Documentos analisados: Folha de rosto, carta de encaminhamento, declaraçán de responsabristose protocolo de pesquisa, termo de consentimento livre e esclarecido, cronograma, bihiografia perinente e currículo (s)' de pesquisador (es).

Data de entrega: $13 / 10 / 2009$.

Proposiçăo do (a) relato (a)

(X) Aprovação

( ) Não aprovação.

Data da primeira análise pelo CEP-FM/UNB: 19/10/2009.

Data do parecer final do projeto pelo CEP-FM/XB: 25/11/2009.

\section{PARECER}

Com base na Resolução CNS/MS no 196/96 e resoluçōes posteriores, que regulameatam a ma:trì o Comitê de Ética em Pesquisa da Faculdade de Medicina da Universidaje de Brastia doctitu APROVAR "ad referendum", conforme parecer do (a) relator (a) o projeco de pesiulice tima especificado, quanto aos seus aspectos éticos.

1. Modificaçōes no protocolo devem ser submetidas ao CEP, assim como a notificay̧o ín imutias de eventos adversos graves;

2. $\mathrm{O}(\mathrm{s})$ pesquisador (es) deve (m) apresentar relatórios perióticos do andamento da pesquilise bo CEP-FM.

Brastila, 26 de Novembro de $20 \mathrm{ir}$

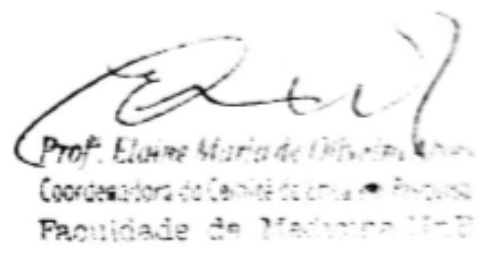

